


\title{
Las remesas internacionales del PTAT y su impacto en el capital humano en México
}

\author{
Román Sánchez Dávila, Lidia Carvajal Gutiérrez \\ y Oswaldo García Salgado
}

\section{UNIVERSIDAD AUTÓNOMA DE CIUDAD JUÁREZ}

PUBLICACIÓN AFILIADA A LA

RED IBEROAMERICANA DE ESTUDIOS DEL DESARROLLO 


\title{
UNIVERSIDAD AUTÓNOMA DE CIUDAD JUÁREZ
}

\author{
PUBLICACIÓN AFILIADA A LA \\ RED IBEROAMERICANA DE ESTUDIOS DEL DESARROLLO
}

Universidad Autónoma de Ciudad Juárez

2018-2024

Mtro. Juan Ignacio Camargo Nassar

Rector

Mtro. Daniel Alberto Constandse Cortez

Secretario General

Mtro. Jesús Meza Vega

Director General de Comunicación Universitaria

Dra. Beatriz Araceli Díaz Torres

Coordinadora General de Investigación y Posgrado

Comité de Coordinación de la Red Iberoamericana de Estudios del Desarrollo 2018-2020

Dra. Paulina Sanhueza Martínez (Universidad de la Frontera, Chile)

Coordinadora General

Dr. Ignacio Rodríguez Rodríguez (Universidad de la Frontera, Chile)

Secretario general

Dra. Myrna Limas Hernández

(Universidad Autónoma de Ciudad Juárez, México)

Vocal de Organización

Dr. Pablo Galaso Reca (Universidad de la República, Uruguay)

Vocal de Organización

Dr. Luis Enrique Gutiérrez Casas

Director y editor de Cuadernos de Trabajo

Estudios Regionales en Economía, Población y Desarrollo

Comité editorial

Sección internacional Dra. Sofía Boza Martínez

(Universidad de Chile, Chile)

Dra. Olga Biosca Artiñano

(Glasgow Caledonian University, Reino Unido)

Dra. Ángeles Sánchez Díez

(Universidad Autónoma de Madrid, España)

Dr. Thomas Fullerton Mankin

(University of Texas at E1 Paso, Estados Unidos)

Dr. Adrián Rodríguez Miranda

(Universidad de la República, Uruguay)

Dra. Ikuho Kochi

(Kanazawa University, Japón)

Sección local

(Universidad Autónoma de Ciudad Juárez)

Dra. Myrna Limas Hernández

Dra. Rosa María García Almada

Dr. Raúl Alberto Ponce Rodríguez

Dr. Isaac Leobardo Sánchez Juárez

Dr. Héctor Alonso Barajas Bustillos

Dr. Juan Carlos Medina Guirado

Diseño de cubierta Abigail Bautista
Estudios Regionales en Economía, Población

y Desarrollo. Cuadernos de Trabajo de la UACJ

ISSN 2007-3739

Número 52. Julio/Agosto 2019

Las remesas internacionales del PTAT y su

impacto en el capital humano en México

Román Sánchez Dávila, Lidia Carvajal Gutiérrez y

Oswaldo García Salgado

Universidad Autónoma de Ciudad Juárez

Estudios Regionales en Economía, Población y Desarrollo.

Cuadernos de Trabajo de la UACJ

Año 9, No. 52 julio - agosto 2019, es una publicación bimestral editada por la Universidad Autónoma de Ciudad Juárez a través del Cuerpo Académico de Estudios Regionales en Economía, Población y Desarrollo. Redacción: Avenida Universidad y H. Colegio Militar, Zona Chamizal s/n., C.P. 32300, Ciudad Juárez, Chihuahua, México. Teléfonos: (656) 688-38-00, ext.3792. Correo electrónico: igtz@uacj.mx.

Editor responsable: Luis Enrique Gutiérrez Casas. Reserva de derechos al uso exclusivo: edición impresa, ISSN 2007-3739., edición digital, No. de reserva 04-2019-050218151500. Impresa por Studio Los Dorados, calle Del Campanario, número 820-2, Santa Cecilia, C.P. 32350, Cd. Juárez, Chihuahua. Distribuidor: Subdirección de Gestión de Proyecto y Marketing Editorial. Ave. Plutarco Elías Calles 1210, Foviste Chamizal, C.P. 32310, Ciudad Juárez, Chihuahua. Este número se terminó de imprimir el 15 de junio, 2019 con un tiraje de 120 ejempares.

Los ensayos publicitarios son responsabilidad exclusiva de sus autores.

Se autoriza la reproducción total o parcial bajo condición de citar la fuente.

Registrada en: EBSCO RePEC

Publicación afiliada a la Red Iberoamericana de Estudios del Desarrollo

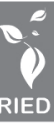

Universidad Autónoma de Ciudad Juárez

Ave Plutarco Elías Calles 1210

Foviste Chamizal, C.P. 32310

Ciudad Juárez, Chihuahua, México

www.uacj.mx

(C) Universidad Autónoma de Ciudad Juárez 


\title{
Las remesas internacionales del PTAT y su impacto en el capital humano en México
}

\author{
Román Sánchez Dávila *, Lidia Carvajal Gutiérrez ** \\ y Oswaldo García Salgado ***
}

\begin{abstract}
Resumen
Este ensayo tiene como propósitos construir un indicador de formación de capital humano a partir de una base de datos propia generada por una encuesta a jornaleros mexicanos que trabajan en Canadá, quienes se encuentran inscritos en el Programa de Trabajadores Agricolas Temporales (PTAT), y desarrollar un modelo LOGIT para detectar factores independientes a los expuestos en las teorías sobre capital humano que tengan intervención positiva o negativa. Conforme a los resultados del modelo se concluye que las remesas que llegan a México por parte de los migrantes inscritos en el PTAT son efectivamente generadoras de capital humano a partir del efecto que tienen los factores exógenos regionales, sociales, económicos y demográficos que fueron considerados.
\end{abstract}

Palabras clave: PTAT, migración, capital humano, remesas, México.

\begin{abstract}
The purpose of this essay is to build an indicator of human capital formation from a database generated by a survey oriented to Mexican workers in Canada registered on CSAWP. It is also our aim to develop a LOGIT model to detect independent factors that may have positive or negative impacts on human capital. We conclude that the remittances from migrants registered on CSAWP are effectively generating human capital, considering the effects that exogenous regional, social, economic and demographic factors have.

Keywords: Impact assessing, value added tax, consumption, Mexico.
\end{abstract}

JEL Classification: CSAWP, migration, human capital, remittances, Mexico.

- Recibido en: Febrero de 2019.

- Aprobado en: Mayo 2019.

\footnotetext{
* Asistente de Investigación de la Facultad de Economía de la Universidad Autónoma del Estado de México.

Correo electrónico: roman.san.dav@gmail.com.

** Profesora investigadora de la Facultad de Economía de la Universidad Autónoma del Estado de México.

Cuerpo académico: Economía Financiera e Internacional. Correo electrónico.lcarvajal_2000@yahoo.com.

*** Profesor investigador de la Facultad de Economía de la Universidad Autónoma del Estado de México.

Cuerpo académico: Economía Financiera e Internacional. Correo electrónico: oswars@gmail.com.
} 


\section{$\rightarrow$ 1. Introducción. $^{1}$}

Diversos panoramas han criticado a la migración internacional a partir de argumentos como la fuga de talentos, la vulnerabilidad de los migrantes ilegales, así como las adversidades psicosociales a las que se enfrentan. Sin embargo, "la otra cara de la migración" centrada en el cooperativismo entre naciones, con programas regulados y coordinados, han propiciado una mayor y más eficiente participación de trabajadores en empleos internacionales con beneficios personales y familiares innegables.

Al concentrarse en la migración laboral las regiones y naciones que tienen emigrantes muestran incrementos graduales y estables en sus niveles de ingreso, gracias al nivel de estabilidad y continuidad que tienen las remesas en el país receptor, debido a su característica anticíclica e inelástica ante sucesos sociopolíticos locales en comparación con la inversión extranjera directa. Diversas fuentes de información oficiales ${ }^{2}$ indican que para 2017 el ingreso en México por concepto de remesas se ha convertido en el tercero de mayor relevancia por nivel de flujo, únicamente superado por la industria automotriz y agroalimentaria. Pero los beneficios de la migración laboral no solamente se encuentran enunciados por los flujos económicos que permiten a los receptores incrementar su ingreso y, con ello, ahorrar, invertir o gastar, sino que los beneficios intangibles son poco estudiados pero muy valiosos, ya que permiten la inversión en capital humano. En otras palabras, el aprendizaje, tanto en el acceso a la educación formal como en la herencia de experiencia, es un activo sin caducidad, por lo que es conveniente analizar a las remesas como fuente formadora de capital humano mediante la inversión en educación y salud y, el impacto desde el punto de vista del conocimiento por medio de la experiencia.

El propósito del presente ensayo es determinar el impacto que llegan a tener las remesas internacionales provenientes de jornaleros mexicanos que trabajan en el Programa de Trabajadores Agrícolas Temporales México-Canadá (PTAT) para la inversión en la formación de capital humano. Para ello se intenta construir un indicador de formación de dicho capital en una primera etapa y, como segunda fase, se desarrolla un modelo de regresión tipo LOGIT que pueda reconocer factores exógenos, alternos a los que mencionan las teorías de Schultz $(1960,1972)$, Becker $(1975,1990)$ y Mincer $(1958,1974)$, los cuales explicarían procesos de aceleración o desaceleración en la formación de capital humano.

\footnotetext{
${ }^{1}$ Este trabajo es uno de los productos del proyecto de investigación "Migración y remesas del PTAT en el Estado de México: un análisis empírico sobre los impactos en la formación de capital humano", registrada ante la Universidad Autónoma del Estado de México, clave: 4466/2017SF.

${ }^{2}$ Periódico El Economista y periódico El Financiero. Notas de diciembre de 2017 consultadas de manera electrónica el 27 de febrero de 2018.
} 
Este estudio confirma que el PTAT contribuye en la formación de capital humano, particularmente a través de aquellas personas que permanecen al programa por más de cinco años, y concluye que es posible estimar un modelo capaz de determinar factores exógenos que muestren los avances y retrocesos en la formación de capital humano en las familias mexicanas que tienen un integrante que participa en el PTAT. El enfoque de la investigación es cuantitativo, debido al uso de estadística para medir los procesos sobre fenómenos sociales, la potencial replicabilidad del estudio, los planteamientos acotados, la posibilidad de realizar pruebas de hipótesis y el uso de teorías previamente planteadas. ${ }^{3}$

El análisis está comprendido en dos fases. En la primera, el alcance de la investigación es exploratorio, ya que con base en la encuesta de Carvajal (2008), y con los fundamentos teóricos necesarios, se construirá un indicador que servirá como variable endógena del modelo, resaltando que el campo de estudio ha sido vagamente analizado y no se han realizados estudios empíricos como los que se desarrollan en este trabajo. En la segunda fase, la investigación será de corte correlacional, ya que, haciendo uso de datos panel e implementando el modelo de regresión logística como técnica de análisis, se conocerán aquellos factores que tengan impactos positivos o negativos sobre la variable dependiente, mismos que detallan y agrupan a los individuos colectivamente con el propósito de ofrecer posibilidades predictivas. ${ }^{4}$

\section{El Programa de Trabajadores Agrícolas Temporales (PTAT).}

El Programa de Trabajadores Agrícolas Temporales (PTAT), surgió en el año 1966 debido a la demanda insatisfecha de mano de obra para el sector primario en la provincia de Ontario Canadá. Como primera etapa, este acuerdo fue firmado con países de la mancomunidad británica, posteriormente, en el año 1974, con la firma de un "Memorándum de Entendimiento" y el "Acuerdo de Empleo Temporal de Trabajadores Agrícolas Mexicanos en Canadá" de 1973, se dio apertura a jornaleros mexicanos para poder acceder al programa. Como objetivo secundario, este acuerdo binacional ha contribuido a regular la migración ilegal México-Canadá. (Trejo \& Álvarez, 2007)

La Secretaría del Trabajo y Previsión Social en México, a través del PTAT, es la encargada de reclutar, seleccionar y promover el flujo de trabajadores agrícolas de México a Canadá. A través del marco jurídico de participación se establece la cantidad demandada de migrantes por

\footnotetext{
${ }^{3}$ Adecuación al panorama de trabajo, con base en lo descrito en (Hernández Sampieri \& Fernández Collado, 2014).

${ }^{4}$ Ibídem.
} 
temporada, las generalidades sobre el contrato, tales como documentación requerida, periodo de contratación, detalles sobre transporte, hospedaje, alimentación, salarios, seguro a los trabajadores así como derechos y obligaciones del trabajador y empleador.

Los trabajadores ingresan por primera vez al programa ${ }^{5}$ cuando tienen entre 22 y 45 años de edad, comprueban tener experiencia en actividades agrícolas, viven en zonas rurales, deben tener entre tercero de primaria y tercero de secundaria como nivel de escolaridad y demostrar estar casados y/o tener dependientes económicos. Los trabajadores nominales son los que ya han participado más de una vez en el programa y son llamados por su empleador canadiense, y los trabajadores de reserva están atentos a llamados inesperados debido a bajas en trabajadores nominales y de selección.

Los jornaleros del PTAT gozan de igualdad de oportunidades salariales y de prestaciones que los trabajadores canadienses en la misma actividad. El transporte aéreo México-Canadá-México es pagado por el empleador al inicio de la temporada y un porcentaje de este, será deducido de la nomina del trabajador. Los empleadores deben proporcionar a sus trabajadores hospedaje con equipo de lavandería, transporte ${ }^{6}$, maquinaria y equipo de seguridad para el trabajo, también por acuerdo podrá proveer de alimentos y seguro con deducción a su salario. La remuneración deberá ser semanal y a los trabajadores que sumen cinco años o más trabajando con el mismo empleador, se les deberá pagar un bono semanal. ${ }^{7}$

El trabajador debe respetar las reglas de la granja y del contrato, trabajar con destreza y responsabilidad únicamente en tareas agrícolas para el empleador que le fue asignado y se compromete a regresar a México al termino del contrato, es decir su estancia en Canadá va de 240 días a 8 meses como máximo.

Hasta el año de 2018 se han enviado más de un cuarto de millón de jornaleros en el PTAT, generalmente la mayor participación se ha concentrado en los estados de México, Tlaxcala, Veracruz y Michoacán. Más del 75\% de los trabajadores que han sido enviados en los últimos cinco años son nominales, cerca del 65\% de los espacios de trabajo que solicita el PTAT han sido cubiertos por mexicanos y el 35\% restante provienen de países del Caribe. Las provincias de Ontario, Quebec y Columbia Británica son aquellas que solicitan el mayor número de jornaleros del PTAT (Veraza López, Carreño González, Cervantes Zavala , \& Loyola Mandolini, 2016).

\footnotetext{
${ }^{5}$ Trabajadores de Selección.

${ }^{6}$ Del lugar de hospedaje a la granja.

${ }^{7}$ Información publicada en la página oficial del gobierno de Canadá "Goverment of Canada", consultado el 26 de septiembre de 2018, disponible en: https:/www.canada.ca/en/employment-social-development/services/foreign-workers/ agricultural/seasonal-agricultural/apply/mexico-spanish.html.
} 


\section{Э 3. Marco teórico.}

Se debe considerar a la migración de jornaleros México-Canadá como un fenómeno migratorio temporal reiterado en el contexto internacional, en el cual, los migrantes deciden desplazarse por su propia voluntad generalmente teniendo como prioridad mejorar su condición económica futura.

La teoría de la nueva economía de la migración laboral contiene un alto nivel de especificidad, observada por múltiples autores como una crítica a la parte microeconómica de la teoría neoclásica atribuida a Stark $(1989,1991)$.

Coincide con la teoría neoclásica en cuanto al objetivo de maximizar la utilidad, pero difiere condicionando dicho objetivo a ser de carácter familiar, y se orienta no hacía incrementar ingresos sino a reducir riesgos por medio de la diversificación de sus fuentes de empleo y disminuyendo el riesgo sobre pérdida de empleo o cultivos. (Arango, 2003)

Es destacable que los jornaleros del PTAT regresan con una estima de victoria en comparación con sus homólogos que decidieron no migrar. La migración internacional obedece a una demanda permanente de mano de obra en las sociedades industrializadas avanzadas creando una segmentación en los mercados de trabajo. Explicada como la necesidad de los países desarrollados de requerir mano de obra calificada de los países de la periferia, esta demanda se caracteriza por ser permanente. Las causas de la demanda de mano de obra son por que los nativos de los países desarrollados consideran denigrante, mal pagado, poco atractiva o riesgosa determinada actividad, y no existe oferta de trabajo nacional. (Arango, 2003).

De acuerdo con Piore (1979), existen en las economías desarrolladas trabajos inestables y de baja calidad intensivos en capital para el sector primario y excesivos en trabajo para el sector secundario, siendo rechazados por los nativos por concebirlos de una posición social baja y sin ofertas de movilidad social, sin embargo estos trabajos no pueden ser incentivados de manera local con incrementos salariales ya que esta política movería drásticamente el precio del trabajo en los empleos considerados superiores, generando inflación estructural. Los trabajadores extranjeros procedentes de países subdesarrollados aceptarán estos empleos ya que podrán recibir mayores beneficios económicos que en su lugar de origen contando con el incentivo de ser temporales. ${ }^{8}$ Por otro lado, estos trabajos no son ocupados por mujeres y jóvenes en los países desarrollados ya que las mujeres pueden ahora dignificar su estatus laboral por la equidad de género, y debido a su consistencia demográfica la disponibilidad de jóvenes es reducida (su población es envejecida, según sus pirámides poblacionales).

Las redes migratorias son originadas por los nexos interpersonales que vinculan a los migrantes actuales, los retornados y los no migrantes en áreas de origen y destino a través de lazos de parentesco, de amistad o por pertenencia a la misma comunidad de origen. Las redes facilitan 
el desplazamiento internacional disminuyendo los costos y riesgos, constituyendo una forma de capital social que permite el acceso a un empleo en el extranjero, siendo una actividad cíclica y en constante expansión. En los que aún no migran, la estructura de la red siembra incertidumbre que les permite visualizar algunos beneficios colaterales que trae consigo cambiar de residencia, ante esto, suelen verse inducidos hasta cierto punto a migrar. ${ }^{9}$ Esta teoría define que la migración internacional es un proceso de decisión familiar o individual, pero altera sistemáticamente el contexto de las decisiones para los migrantes potenciales incrementando de manera abrupta las posibilidades de que muevan su residencia por motivos laborales. (Massey, y otros, 1993).

Para Massey (1987), las redes migratorias son consideradas como una forma de capital social, ya que al tratarse de relaciones sociales permiten el acceso a bienes económicos como el empleo o las mejoras salariales tras frontera. En este mismo análisis, las redes migratorias pueden verse constituidas como instituciones que actúan a manera de intermediarios ${ }^{10}$, cuya misión es apoyar a los migrantes a superar las dificultades de entrada y asentamiento en el país de destino.

La distribución regional del capital humano. ${ }^{11}$ La migración es un proceso selectivo que tiende, al menos inicialmente a apartar de las comunidades de origen a una población bien educada, cualificada, productiva y altamente motivada (aunque como se describe anteriormente, la migración tiende a ser menos selectiva con el paso del tiempo en tanto que los costos y riesgos descienden por la formación de redes). Esta migración conduce a un agotamiento del capital humano en las regiones de origen y su acumulación en las áreas de destino, mejorando la productividad de los últimos y descendiendo en los primeros. Por lo tanto, a lo largo del tiempo, la acumulación de capital humano refuerza el crecimiento económico en las áreas de destino mientras que simultáneamente lo agota en las de origen exacerbando su estancamiento. (Myrdal, 1957; Greenwood, 1981, 1985; Greenwood, Hunt y McDowell, 1987) ${ }^{12}$. Los proyectos para la construcción de escuelas y la expansión educacional en las áreas de destino refuerzan el proceso de migración acumulativa al aumentar los niveles educativos en las áreas rurales periféricas incrementando los beneficios potenciales de la emigración y otorgándole a la población enormes incentivos para partir hacia destinos urbanos en casa o en el extranjero (Massey, y otros, 1993).

\footnotetext{
${ }^{8}$ Se considera que el ser temporales los incentiva ya que ellos piensan en retornar con su familia a su lugar de origen.

${ }^{9}$ Llamado "efecto demostración" (Arango, 2003).

${ }^{10}$ Consideradas desde redes de contrabando, hasta organizaciones de carácter laboral, filantrópico y humanitario.

${ }^{11}$ Como parte de la teoría de la acumulación causal.

${ }^{12}$ Citado en (Massey, y otros, 1993).
} 
La visión crítica de las remesas es el más reciente y en un acertado análisis Canales (2004) enuncia tres aspectos de este enfoque:

i. Se asimila el uso de las remesas como fondo salarial de origen externo, justificado por la alta participación que tienen en el ingreso de los hogares que permiten acceder a niveles mejores de consumo y bienestar que cuando no estaban vinculados a la migración. También gracias a la permeabilidad y estabilidad que presenta el ingreso por concepto de remesas, podemos definirlo con tendencia anti cíclica e inflexible a la baja, es decir, ante un periodo de recesión o crisis, se produce un desajuste en el balance consumo-ingreso reduciendo los niveles de ambos, sin embargo, en este periodo las remesas permiten mantener los mismos niveles de consumo. Así se reafirma el postulado de que las remesas no son una forma de ahorro migrante, sino una transferencia salarial, cuyos usos y efectos son similares a los de cualquier otro salario para financiar la reproducción familiar.

ii. Las remesas tienen limitaciones como fuentes de inversión, ya que al considerarse un instrumento de inversión productiva en contextos regionales figuran ante la virtual ausencia de otras fuentes de financiamiento. En cuanto a inversión pública, el Estado tiene en un parcial abandono a esta región por disfunciones en sus políticas públicas, y en lo que respecta a financiamiento privado, las instituciones se encuentran poco motivadas por proveer de recursos financieros a estas zonas ya que le temen al fracaso por considerarlas poco rentables y/o riesgosas, siendo las remesas el único motor de financiamiento para la familia del migrante. El punto aquí es ver a las remesas como complemento más que como agente de solución ante la debilidad del estado y de los agentes privadas por la ausencia de una buena política de desarrollo local, sin olvidar que deben vincularse a la reproducción material de la familia más que a la creación de negocios, porque aunque se destinen a proyectos, estos tendrán un efecto multiplicador diminuto ya que van orientadas a pequeños establecimientos de alcance local que poco participarán en la creación de un polo de desarrollo. ${ }^{13}$

iii. Las remesas tienen efectos multiplicadores donde Binford (2002) detalla que los agro negociantes y capitalistas, aunque no emigran se benefician de los efectos indirectos de migrar, ya que ellos producen lo que las familias de los migrantes van a consumir con las remesas que reciben, poniendo en tela de juicio si realmente los beneficios de estas van en dirección regional, o son las zonas urbanas (por cuyo contexto industrial y de servicios) quien se lleva mayores ganancias. En conjunto se cuestiona el efecto multiplicador 2.9 mencionado en el enfoque funcionalista ya que más bien debe contemplarse como un acumulado de las remesas. ${ }^{14}$ 
"Calcular la inversión humana a través de su rendimiento más que a través de su coste. Mientras que cualquier aumento de la capacidad producida por la inversión humana se convierte en una parte del agente humano y por lo tanto no puede ser objeto de venta, está, sin embargo, "en relación con el mercado" al afectar a los sueldos y los salarios que puede percibir el agente humano. El aumento resultante de los ingresos es el rendimiento de la inversión” (Schultz T. , 1972, pág. 23).

En numerosas obras ${ }^{15}$ Schultz se refiere a la educación como un factor exógeno que beneficia el crecimiento económico y el desarrollo de la capacidad humana adjunto al factor trabajo y con beneficios indirectos hacia el capital, es decir, se observa el fomento a la educación como incentivo para la formación humana, que visto desde el factor trabajo trae consigo incrementos en los niveles de productividad y especialización productiva, y a la par generan rendimientos crecientes para la formación de capital físico, mismos que a futuro intervendrán en la producción. Hay que destacar que el trabajo es heterogéneo cuando se contempla desde las capacidades y cualidades laborales, tomando en cuenta a la "calidad" como eje diferenciador de dicho trabajo, manifestado exclusivamente por el nivel de educación que cada trabajador tenga. Por otro lado, haciendo énfasis en la pobreza, se debe invertir en bienestar para la calidad de la población ya que esto determina en gran parte las perspectivas futuras de la humanidad y los gobiernos deberán ocuparse principalmente en las zonas donde más de la mitad de la población vive en condiciones de pobreza, teniendo salarios muy bajos que son destinados en más del 50\% para adquisición de comida, en estas áreas es necesario incrementar la calidad de la población mediante los adelantos en conocimiento e incrementos en las condiciones salubres de la población. (Martínez De Ita , 1997).

Becker (1975) define al capital humano como el conjunto de las capacidades productivas que un individuo adquiere por acumulación de conocimientos generales o específicos:

i. Analiza distintas clases de capital humano, tales como educación escolar (formal) y educación en el trabajo (no formal), y su análisis produce una teoría general de amplias aplicaciones que cubre desde la distribución personal de las ganancias, hasta los efectos del desempleo entre las personas de poca educación. También resume las ganancias de este factor sobre la productividad en Norteamérica.

\footnotetext{
${ }^{13}$ Aquí el autor evalúa la teoría con la práctica y encuentra que, aunque sea pequeño el monto destinado como remesas productivas, en la práctica es una forma sana de capitalizar negocios.

${ }^{14}$ Es decir, un sobre efecto, el 2.9 se constituirá por el efecto multiplicativo generado por el fomento a la inversión productiva y al consumo en el país origen del migrante, motivo por el cual, no es un acelerador de la economía direccionado como la IED, y se calcula que cada dólar ingresado por concepto de remesas generara 2.9 dólares en el PIB local.

${ }^{15}$ Schultz (1970) "Education and economic growth", Schultz (1960) "Investing in people: The economics of population quality”. Citado en (Martínez de Ita, 1997).
} 
ii. Un individuo genera gastos para invertir en educación que a corto plazo le harán permanecer en el mercado laboral de forma inactiva, pero involuntariamente se encuentra generando un costo de oportunidad futuro que será el definitivo para el acceso a mejores condiciones laborales y salariales que benefician a la inversión y productividad de un país, pero, no olvidemos que se debe agregar la motivación e intensidad del esfuerzo del individuo para observar productividades avanzadas.

iii. Considera que la escolarización, la formación, la cultura, la movilidad, etc., representan formas de inversión en capital humano, cuya propensión a invertir por parte de la ciudadanía joven se determina generalmente alta $^{16}$, ya que se observa una vasta capitalización del recurso invertido en plazos futuros.

Posteriormente, surge la visión generada por Mincer (1958 y 1974) en las que se hace hincapié en las bondades económicas y sociales que genera fomentar los años de escolaridad de los individuos, pero, también considerando que aquellos que no puedan asistir a las aulas, mediante la adopción de técnicas laborales al paso de los años y de la usanza humana, van a incrementar su nivel de capital humano. Pero existe una diferencia importante entre el aumento de ingresos relacionado con la edad, y el aumento relacionado con la experiencia laboral, es decir la experiencia laboral se mide desde el momento en que el individuo dejó las aulas hasta el tiempo presente, por lo cual descubre que si un individuo dejó antes de estudiar por consiguiente tendrá una mayor experiencia laboral, sin embargo econométricamente los individuos que tienen más años de escolaridad aunque menor experiencia tienen ingresos más altos, por lo que la experiencia es parte del capital humano pero con significancia inferior a la que presentan los años de estudio (Mincer, 1974).

De manera analítica Giménez (2005) sugiere que el capital humano procede de dos fuentes. La primera es innata y son las cualidades y capacidades con las que nace un individuo y que son fomentadas por la alimentación y las condiciones de salud. La segunda es por la vía de adquisición, bajo la propuesta de que esta vertiente es alimentada gracias a los años de escolaridad y la experiencia de vida donde el tiempo juega un papel determinante y supone que a mayores años de escolaridad y mayor tiempo de vida el ser humano gozará de niveles superiores de capital humano fomentando la dotación innata del individuo.

\footnotetext{
${ }^{16}$ Becker (1975) observa que la propensión a invertir en capital humano, es decir dedicar tiempo, esfuerzo y recursos (financiados por los padres y por el estado), en la ciudadanía joven es generalmente alta, ya que esta inversión tendrá un plazo muy largo de beneficios económicos que incrementan su nivel de vida futuro, caso contrario con los adultos que invierten en educación, sus beneficios van a ser por un periodo corto, por ello la motivación a estudiar se encuentra en los jóvenes. Otro factor, que motiva a los jóvenes es porque los padres invierten en sus hijos el dinero que podían invertir en ellos.
} 


\section{○.Técnica empleada.}

Los trabajos de investigación en la ciencia económica se caracterizan mayormente por la fusión de recursos teóricos adoptados de los modelos que se adecuen a los intereses de la investigación, con recursos estadísticos y/o econométricos que demuestren y validen la aplicación de la teoría con la realidad en el análisis.

Generalmente es útil el análisis de regresión lineal simple o multivariable debido a que la composición de los modelos se efectúa con variables dependiente (s) e independientes métricas, la situación cambia, cuando la investigación pretende determinar casos no métricos en el estudio. Para tal situación, generalmente sobre investigaciones de corte cualitativas o cuantitativas descriptivas, el autor deberá echar mano de recursos diferentes, es ahí donde el análisis discriminante y la regresión logística toman relevancia (Martínez Rodríguez, 2008).

\subsection{El Modelo LOGIT.}

La regresión logística es una técnica estadístico-inferencial empleada en la producción científica contemporánea cuyo surgimiento data de la década de los sesenta; su objetivo es valorar la contribución de diferentes factores en la ocurrencia de un evento simple representado en la variable endógena, misma que principalmente será dicotómica categórica (de la Fuente Fernández, 2011) y la cual predice directamente la probabilidad de ocurrencia de un suceso tomando el parámetro de 0 a $1 .{ }^{17}$ Para modelos cuya variable dependiente es categórica la regresión lineal no es opción, debido a que en primer lugar el término de error de una variable discreta sigue una distribución binomial en lugar de la distribución normal cosa que invalida los supuestos de normalidad, en segundo lugar, la varianza de una variable dicotómica no es constante, creando en consecuencia heterocedasticidad.

\subsection{Particularidades del modelo de regresión LOGIT. ${ }^{18}$}

1. Los modelos cuya variable endógena es dicotómica pueden resolverse por el método de Fisher (método generado a partir del llamado análisis discriminante) y por la modelización logística.

2. El modelo LOGIT es similar a la regresión tradicional, pero con la diferencia de hacer uso de la función logística.

3. Se usa para estimar la probabilidad de que un nuevo individuo pertenezca a un grupo o a otro $(0,1)$, y al tratarse de un análisis de regresión también permite identificar las variables exógenas más importantes que explican las diferencias entre grupos.

${ }^{17}$ Donde para niveles muy bajos de la variable independiente la probabilidad se aproxima a cero y una aproximación probabilística a 1 cuando los niveles de acercamiento son altos.

${ }^{18}$ Profesora Medina Moral, Eva. “Análisis Discriminante con Metodología LOGIT”, Universidad Autónoma de Madrid, Madrid España, Apuntes de clase, (2003). Disponible en:

https://www.uam.es/personal_pdi/economicas/eva/pdf/dis_logit.pdf. 


\subsection{Modelo LOGIT dicotómico.}

Dada la composición de las variables, se empleará un modelo LOGIT dicotómico, las principales características son:

1. Variable Endógena Binaria: Identifica la pertenencia del individuo a cada uno de los grupos analizados.

a. Se identifica con un 1 al individuo que pertenece al grupo cuya probabilidad de pertenencia estimará el modelo.

b. Se identifica con un 0 al individuo que no pertenece al grupo objeto de análisis.

2. Variables explicativas: Son las variables que sirven para discriminar entre los grupos y que determinan la pertenencia de un elemento a un grupo u otro. Pueden ser:

a. Variables cuantitativas cuyo campo de variación entre $-\infty$ hasta $+\infty$.

Variables cualitativas con distintas alternativas de codificación, según la fuente de proce-

b. dencia y el criterio del investigador.

\subsection{Representación de la función LOGIT}

El propósito de una regresión radica en encontrar la relación existente entre la o las variables explicativas $\left(X_{i}\right)$ con la variable endógena $(Y)$.

Generando la modelización lineal primaria tenemos que:

$$
Y=\beta_{0}+\beta_{i} X_{i}+u
$$

\section{Donde:}

\section{$Y=\quad l$ si ocurre el acontecimiento. 0 en caso contrario. \\ $X_{i}=\quad$ Conjunto de variables exógenas (explicativas). \\ $u=\quad$ Termino de error del modelo.}

La estimación de este modelo tendrá los siguientes problemas debido a la dicotomía en la variable dependiente:

i. No existirá normalidad en los errores.

ii. Heterocedasticidad, dicho problema podría resolverse mediante la estimación de mínimos cuadrados generales. ${ }^{19}$

iii. El rango de variación de la estimación no se encuentra acotado entre 0 y 1 , lo cual carece de sentido cuando lo que se pretende estimar es una probabilidad. 
Estos problemas son fácilmente corregidos mediante el uso de funciones no lineales en la modelización para que se permita acotar el rango de la estimación, es decir mediante el uso de alguna función de distribución este problema será resuelto, las opciones de modelos LOGIT y PROBIT ${ }^{20}$ son las más comúnmente usadas, sin embargo, debido a la aplicación práctica y la mayor simplicidad ante la interpretación y computo, el modelo logístico es el preferido.

La estimación del modelo logístico quedará de la siguiente manera:

$$
Y=\frac{1}{1+e^{\beta_{0}+\beta_{i} X_{i}}}+u
$$

De esta forma los valores de la función ahora si variarán entre el rango [0-1] y se interpretarán como la probabilidad de ocurrencia del acontecimiento objeto de estudio.

Dicha estimación a diferencia de la regresión lineal, no se realiza mediante la aplicación de mínimos cuadrados ordinarios, sino que se hace uso del proceso de máxima verosimilitud, utilizando de forma iterativa para encontrar la "estimación más probable" (Medina Moral, 2003).

\subsection{Interpretación de los coeficientes.}

La ventaja de esta forma de modelar es que solamente necesitamos saber si un suceso ocurrió o no para entonces proveer del valor dicotómico a nuestra variable dependiente. ${ }^{21}$ La función logística puede expresarse como una función lineal, quedando de la siguiente forma.

$$
\ln \left(\frac{Y_{i}}{1-Y_{i}}\right)=\ln \left(e^{\beta_{0}+\beta_{i} X_{i}}\right)=\beta_{0}+\beta_{i} X_{i}
$$

Con lo cual, la interpretación de cada coeficiente estimado debe realizarse de la siguiente forma:

i. El signo del coeficiente $\left(\beta_{0}, \beta_{1}, \ldots, \beta_{i}\right)$ indica la dirección en que se mueve la probabilidad de pertenencia en el grupo " 1 " al aumentar la variable explicativa a la que corresponde el coeficiente.

ii. La cuantía del parámetro indica el incremento en $\ln \left(\frac{Y_{i}}{1-Y_{i}}\right)$ al incrementar en una unidad de una variable explicativa cuando el resto de las variables explicativas permanecen constantes.

\footnotetext{
${ }^{19}$ Sin embargo, dicha metodología puede ser opción únicamente para modelos de estimación con variables repetidas.

${ }^{20}$ Esta emana de la función de distribución normal tipificada.

${ }^{21}$ Estos valores también pueden ser arbitrarios de acuerdo a una respuesta cualitativa. (Montgomery, Peck, \& Vining, 2006).
} 
iii. El procedimiento que calcula el coeficiente logístico compara la probabilidad de la ocurrencia de un suceso con la probabilidad de que no ocurra se expresa en la ecuación 4.

$$
\frac{\operatorname{Prob}_{(\text {evento })}}{\operatorname{Prob}_{(\text {no evento })}}=e^{\beta_{0}+\beta_{1} X_{1}+\cdots+\beta_{n}+X_{n}}
$$

Donde los coeficientes estimados representan en realidad medidas de los cambios en la ratio de probabilidades denominados odas ratio $^{22}$ expresadas en logaritmos, un coeficiente positivo aumenta la probabilidad mientras que uno negativo disminuye la probabilidad predicha, a la vez que estos coeficientes deben representar efectivamente relaciones no lineales entre las variables dependiente e independientes.

El valor de $e^{\beta_{i}}$ mide el efecto del incremento de una unidad de la variable explicativa según

corresponda sobre $\frac{Y_{i}}{1-Y_{i}}$, siendo este el "odds ratio", y permite cuantificar el numero de veces que es más probable que ocurra el acontecimiento que se asocia con $Y_{i}=1$ que el asociado con $Y_{i}=0$.

\subsection{Valoración de la bondad del ajuste del modelo estimado.}

Este modelo requiere evaluar el modelo de las siguientes formas:

i. La medida global de cómo se ajusta el modelo, es similar al valor de la suma de los errores o residuos al cuadrado en la regresión múltiple, viene dada por la verosimilitud siendo “-2 veces el logaritmo del valor de verosimilitud y se representa como -2LL o -2 veces el logaritmo de verosimilitud". Un ajuste perfecto tiene una verosimilitud de 1 y -2LL es cero.

ii. Para este procedimiento se calcula la ratio de verosimilitud total del modelo (toma en cuenta todas las variables explicativas), con el valor de verosimilitud calculado para el modelo restringido (solo considera la constante del modelo).

$$
\text { Ratio de verosimilitud }=1-\frac{L(\text { modelo })}{L(\text { restringido })}
$$

iii. El ratio calculado tendrá valores comprendidos entre 0 y 1 de forma que cuando el modelo ajustado sea perfecto valdrá $1 .{ }^{23}$

iv. El contraste chi cuadrado para la reducción del logaritmo del valor de verosimilitud proporciona una medida de mejora debida a la introducción de variables independientes.

\footnotetext{
${ }^{22} \mathrm{Su}$ interpretación es la "ventaja" o preferencia de la opción 1 frente a la 0 , es decir, el número de veces que es más probable que ocurra el fenómeno frente a que no ocurra.

${ }^{23}$ Profesora investigadora tiempo completo en la Facultad de Economía UAEMex.
} 
v. Se puede construir un valor pseudo $\mathrm{R}^{2}$ para la regresión logística, similar al valor del $\mathrm{R}^{2}$ del análisis de regresión calculado como:

$$
R_{\text {Logit }}^{2}=\frac{2 L L_{\text {nulo }}-\left(-2 L L_{\text {model })}\right)}{-2 L L_{\text {nulo }}}
$$

Ahora bien, para evaluar el ajuste global de nuestro modelo se realizan pasos similares a la regresión múltiple, haciendo uso de varios métodos que contemplan la característica no métrica de la variable endógena:

i. Podemos utilizar el método de las matrices de clasificación del análisis determinante para evaluar la exactitud predictiva en términos de pertenencia al grupo.

ii. Para un acercamiento a la predicción real de la variable, Hosmer y Lemeshow citado en (Hair, Anderson, Tatham , \& Black, 1999, págs. 283-284) plantean dividir los casos en 10 clases aproximadamente iguales, luego el número de sucesos reales y predichos se compara en casa clase con el estadístico Chi-cuadrado, esta medida no se basa en el valor de la verosimilitud.

Finalmente, para valorar la significancia estadística de cada coeficiente, a diferencia de la regresión lineal donde se usa el estadístico t, aquí haremos uso del estadístico de WALD (Hair, Anderson, Tatham, \& Black, 1999).

\section{Antecedentes de la muestra.}

Para la elaboración del modelo, se hará uso de la encuesta aplicada por Carvajal $(2008)^{24}$ en su trabajo de tesis doctora ${ }^{25}$ donde contempla a 257 mexicanos participantes del PTAT que se encontraban trabajando en comunidades rurales del sur de la provincia de Ontario Canadá. La entrevista estuvo organizada en cinco secciones: la primera, acerca de los entrevistados y sus características sociodemográficas; la segunda, sobre su experiencia laboral en Canadá, los factores que los motivaron para decidir participar en el PTAT y detalles sobre su contrato, horas trabajadas e ingreso; la tercera sección captura las actividades que realiza el migrante en México y que realizará a su retorno; la cuarta sección describe los impactos económicos en México debido a los diferentes usos que los migrantes les dan a las remesas y, finalmente, la quinta sección considera la problemática de los procesos agrícolas en México. Estas preguntas fueron capturadas en un cuestionario de 127 reactivos, muchas de ellas no contribuyen a los objetivos del artículo, por tanto, previo a la modelización se realizó una selección, resultando útiles alrededor de 50 preguntas. 
La estadística descriptiva de la muestra tiene las siguientes características:

a. Se encuestó a 257 individuos, de los cuales únicamente cuatro fueron mujeres.

b. Las edades van de los 24 a 60 años siendo el promedio de edad 39 años, la moda en edades es de 36 y 37 años con 19 observaciones.

c. En cuanto a situación civil, 210 eran casados (81.7\%), dos solteros (.8\%), 43 vivían en unión libre (16.7\%) y dos eran divorciados (.8\%).

d. El número de hijos por encuestado va de cero a ocho hijos; sin embargo, la persona que más dependientes económicos tiene llega a siete. La media en el número de hijos económicamente dependientes es de 3.21 y la moda es de tres hijos.

e. El 17.9\% de los encuestados indicó haber emigrado a Estados Unidos anteriormente, el $82.1 \%$ afirman no haberlo hecho.

f. La cifra acumulada de años consecutivos que tienen los migrantes participando en el PTAT va de uno a 21 años, el promedio de la muestra es de 7.80 años, el dato más frecuente corresponde a seis años con 30 observaciones.

g. El tiempo de contrato para la temporada 2006 como lo estipulan los lineamientos del PTAT puede ser de entre dos y ocho meses, para los casos observados la media de permanencia en ese año fue de 5.93 meses, pero siete meses fue la moda de los datos ya que 68 migrantes permanecieron ese tiempo en Canadá.

h. El promedio de horas trabajadas en semana normal fue de 64.24 horas por persona, la moda para esta misma observación fue de 60 horas. En semanas altas de producción en promedio los migrantes trabajaron 74.19 horas el dato con mayor número de observaciones repetidas fue de 80 horas. Finalmente, en semanas cuya producción es baja, se trabajó en promedio 56.32 horas y 55 horas fue la cifra correspondiente a la moda.

i. El ingreso por hora fue de $\mathrm{CAD} \$ 8$ o $\mathrm{CAD} \$ 9$ por hora, el $95 \%$ de los migrantes gana $\mathrm{CAD} \$ 8$ con o sin centavos, solamente el 5\% llega a los CAD \$9.

j. 107 encuestados estuvieron seguros de recibir bono en esa temporada, 110 no lo recibirían dado que aún no cumplían el tiempo de permanencia con el mismo empleador, y otros 40 no sabían.

k. El ingreso del bono fue entre $\mathrm{CAD} \$ 150$ y $\mathrm{CAD} \$ 900$, la mayor parte de los que sí recibieron ese ingreso fue por $\mathrm{CAD} \$ 300, \mathrm{CAD} \$ 400$ y CAD $\$ 430$. Únicamente ocho participantes obtuvieron CAD $\$ 900$.

\footnotetext{
${ }^{24}$ Profesora investigadora tiempo completo en la Facultad de Economía UAEMex.

${ }^{25}$ Carvajal Gutiérrez, Lidia. Farm-level impacts in Mexico of the participation in Canada's Seasonal Agricultural Workers Program (CSAWP), 2008, Doctoral Thesis, University of Guelph.
} 
1. El ingreso neto en esa temporada fue de $\operatorname{CAD} \$ 2,900$ a $\mathrm{CAD} \$ 14,500$, la media se concentró en CAD $\$ 9,339$ y la moda en CAD $\$ 11,000$.

m. En promedio CAD\$91.57 mensuales per cápita es lo que gastaban para sus necesidades básicas en Canadá.

n. La edad del cónyuge va de los 18 a 64 años, la media de edad grupal es de 35 años, la moda fue de 33 años.

o. El 100\% de los trabajadores envía dinero a México, 3.5\% lo hace de forma semanal, $42.8 \%$ de manera quincenal, $49.4 \%$ mensualmente y $4.3 \%$ bimestralmente.

p. El total de dinero que enviaron los trabajadores agrícolas encuestados a México, va de CAD \$2,160 a CAD\$11,600, esta cantidad es menor que el ingreso neto debido a que se deducen los impuestos y los gastos de vida, también la mayoría de ellos compró ropa, artículos electrónicos y demás souvenirs para su familia. Es importante mencionar que muchos de los trabajadores tienen crédito en tiendas departamentales en Canadá. La media de dinero enviado por migrante a México fue de CAD $\$ 6,657$.

q. El gasto promedio en consumo anual que efectuó cada uno con su familia en 2005 fue de CAD\$3,707.

r. El ingreso promedio externo al canadiense que tienen en México es de CAD\$2,083 anuales.

\section{$\Rightarrow$ 6. Desarrollo y resultados del modelo. ${ }^{26}$}

Esta investigación consta de dos fases, la primera se encuentra encaminada a la formación del indicador de capital humano. La segunda fase es la estimación y validación estadística del modelo LOGIT para determinar los factores de impacto en la formación de capital humano. Es prudente resaltar que el indicador que de la primera fase será la variable categórica dicotómica dependiente del modelo en la segunda fase.

\subsection{Primera fase: construcción del indicador de capital humano.}

Considerando el contexto, los objetivos y la técnica del trabajo, el primer punto es obtener la variable dicotómica y categórica que será el factor endógeno del modelo. Al no existir dicha variable, se tiene que construir a partir de las teorías del capital humano y las variables que contiene la muestra. La propuesta de modelo para la formación de la variable dicotómica esta expresada en la ecuación 7.

$$
Z_{C H}=Z_{E S}+Z_{E x}+Z_{S}
$$




\section{donde:}

$Z_{C H}=$ Expresa al conjunto de factores que determinan según los recursos teóricos ${ }^{27}$ a la formación de capital humano.

$Z_{E s}=$ Es el conjunto de variables de la muestra que tienen incidencia directa sobre el factor Educación. ${ }^{28}$

$Z_{E x}=$ Es el conjunto de variables de la muestra que tienen incidencia directa sobre el factor Experiencia. ${ }^{29}$

$Z_{S}=$ Es el conjunto de variables de la muestra que tienen incidencia directa sobre el factor Salubridad. ${ }^{30}$

determinante y el 1 un evento determinante para la formación de capital humano, la segunda etapa consiste ponderar los valores para cada factor y a la vez para cada variable, efectuar la suma producto de la misma y determinar que migrantes cumplen con el valor de esta suma en al menos 0.8 para contemplarlos como formadores.

a) Primera etapa: selección de variables y criterios de recodificación.

La primera etapa consiste en la selección de las variables de la muestra que tienen incidencia directa en los tres factores del capital humano, estas variables son tanto nominales como ordinales según sea el caso de la pregunta y respuesta o respuestas, el objetivo en esta etapa es que, considerando los factores teóricos y a juicio propio, se pueda delimitar cuando en cada variable exista o no exista evidencia de formación de capital humano, tanto en el migrante como en su familia, y que estas queden finalmente codificadas con 0 y 1 según sea el caso. (Véase anexo 1 para conocer las variables en tomadas en cuenta).

\section{b) Segunda etapa: criterios de ponderación para formar el indicador.}

Hasta este punto, ya tenemos cada variable en cada observación codificada en escala binaria, ahora es tiempo de otorgar el peso estadístico que le corresponde a cada variable (véase Anexo 2). En conjunto la suma de las variables que determinan el factor escolaridad tendrá una representatividad del $50 \%$, las variables incluidas en el factor experiencia participarán con un $25 \%$ y finalmente las del factor salubridad tendrán un valor del $25 \%$. Conociendo el peso estadístico de cada variable y el valor 0 o 1 que tiene cada variable para cada migrante, se procede a realizar la suma-producto, el resultado

${ }^{26}$ Se hizo uso del software SPSS V.21 y de hojas de calculo de Microsoft Excel.

${ }^{27}$ Los factores son considerados con las teorías de Schultz $(1960,1972)$, Becker $(1975,1990)$ y Mincer $(1958,1974)$.

${ }^{28}$ El factor educación es incluido en las teorías de Schultz $(1960,1972)$, Becker $(1975,1990)$ y Mincer $(1958,1974)$ sobre capital humano.

${ }^{29}$ El factor experiencia es considerado por Becker $(1975,1990)$ como "la educación informal”, y tal cual como experiencia por Mincer $(1958,1974)$.

${ }^{30}$ Las condiciones de salubridad son consideradas por Schultz $(1960,1972)$ como determinantes del capital humano. 
de dicha operación se encuentra acotado entre 0 y 1 . Se decide que los migrantes cuyo valor de la suma-producto sea igual o superior a 0.80 serán los formadores efectivos de capital humano quienes tendrán el valor 1 del indicador, y aquellos que estén por debajo de 0.80 indican no formación y estarán encriptados con el número 0. El resultado final fue que 199 migrantes de la muestra fueron catalogados como "no formadores" y 58 como "formadores de capital humano".

\subsection{Segunda fase: definición de los factores exógenos.}

El modelo incluyó en el bloque inicial a 112 variables de las cuales 24 son directas de la muestra $^{31}$ y el resto son variables de agrupación dummy para fines de interpretación final en el modelo. Sin embargo, dado que el modelo es iterativo, en cada paso fue desechando variables y en el paso final, únicamente 17 factores exógenos tuvieron impactos positivos o negativos para la formación de capital humano.

Finalmente, la ecuación del modelo fue la siguiente:

$$
Z_{C H}=\frac{1}{1+e^{\beta_{0}+\beta_{1} X_{1}+\cdots+\beta_{17} X_{17}}}
$$

\subsection{Interpretación de resultados: análisis de los factores con impacto positivo.}

Los factores con impacto positivo resultantes del modelo se pueden apreciar, en primer término, en el cuadro 1.

Cuadro 1

Factores de impacto positivo en la formación de capital humano

\begin{tabular}{|c|c|c|c|}
\hline Variable & Nombre & $\begin{array}{c}\text { Signo del } \\
\text { coeficiente } \\
\text { exponencial }\end{array}$ & $\begin{array}{c}\text { Valor del } \\
\text { coeficiente } \\
\text { linealizado }\end{array}$ \\
\hline $\mathrm{X}_{2}$ & DUMEstResid4 & + & 2429.637 \\
\hline $\mathrm{X}_{4}$ & DUMEstResid9 & + & 185.584 \\
\hline $\mathrm{X}_{3}$ & DUMEstResid5 & + & 61.071 \\
\hline $\mathrm{X}_{5}$ & DUMEstResid17 & + & 31.601 \\
\hline $\mathrm{X}_{10}$ & DUMTotalAñosPtat7_12 & + & 4.38 \\
\hline $\mathrm{X}_{17}$ & DUMMexicanincome2 & + & 3.85 \\
\hline $\mathrm{X}_{13}$ & DUMIngresoNet3 & + & 3.358 \\
\hline $\mathrm{X}_{9}$ & TotalAñosPtat & + & 1.307 \\
\hline $\mathrm{X}_{1}$ & EstResid & + & 1.262 \\
\hline
\end{tabular}

Fuente: Elaboración propia.

\footnotetext{
${ }^{31} \mathrm{Si}$ requiere mayor información sobre el proceso de codificación, la lista de variables exógenas o generalidades de la muestra, solicitar el recurso a los autores.
} 
Este grupo de factores, sin importar la cuantía de la probabilidad de pertenencia, por el signo que resultó de la regresión, nos muestra a aquellas que tienen impactos positivos en la variable endógena, es decir todos estos factores nos indican que los individuos que tengan asociación con uno o más de estos podrán ser pertenecientes al grupo de los formadores de capital humano.

Los estados de residencia de los migrantes, que el modelo nos descifra como formadores de capital humano son los Estados de Campeche (DUMEstResid4), Chiapas (DUMEstResid5), Ciudad de México (DUMEstResid9) y Morelos (DUMEstResi17). Debido a la localización geográfica y a las características de la población se forman dos grupos para generalizar el análisis.

El primer grupo incluye a los migrantes residentes del estado de Morelos y de la Ciudad de México $^{32}$, algunas de las probables razones que afirman la participación positiva en la formación de capital humano son:

i. Considerando las cifras, únicamente cinco individuos (1.9\%) de la muestra residen en la Ciudad de México y 15 (5.8\%) en Morelos.

ii. La ciudad de México es la mayor acaparadora de escuelas de nivel superior en la República Mexicana, no es de extrañarse que personas de todos los estados decidan estudiar en la capital, este efecto se incrementa cuando la proximidad geográfica y las vías de comunicación dan fácil acceso, tal es el caso de Morelos con la Ciudad de México. Los habitantes de Morelos tienen concebida a la UNAM ${ }^{33}$ (cuyas sedes más importantes se localizan en Ciudad de México) como su mayor aspiración para tener estudios superiores, en conjunto, la propia UNAM, el IPN ${ }^{34}$, y la Universidad Autónoma Chapingo son las universidades con el costo más bajo por estudiante de toda la república, entonces es opción si se considera que los jornaleros están teniendo ingresos superiores que lo que recibían en México y a la par ellos analizan la diversificación de sus gastos y optimizan estas cifras enviando a sus hijos a estas escuelas en la Ciudad de México.

iii. El gobierno de la Ciudad de México se ha caracterizado por su nivel de asistencia social en los últimos años, para todos hay subsidios al transporte, colegiaturas, uniformes, útiles escolares, además de contar con becas para todos los niveles educativos, por tanto, los hijos de migrantes de la capital ${ }^{35}$ tienen mayores oportunidades y beneficios para acceder a la educación formal.

iv. Para el caso Ciudad de México, la aglomeración productiva principalmente de los sectores secundario y terciario es enorme, es la ciudad mexicana con mayor oferta de empleo, y los trabajadores a su retorno es muy probable que desempeñen labores no agrícolas de algún oficio que tengan, he aquí la evidencia de formación de capital humano, muchos de ellos además de conocer el trabajo de labrar la tierra son plomeros, herreros, carpinteros, etc., y obtienen ingresos por dicha actividad. También los cónyuges desempeñan actividades independientes al hogar que fortalecen el ingreso total de la familia, debido a estos ingresos mayores, la familia tiene 
acceso a cultura, esparcimiento, tecnologías de la información y a gasto en prevención y atención a la salud. Y de nuevo, la ciudad de México es la entidad de la Republica que cuenta con la mayor cantidad y calidad de los espacios culturales, de esparcimiento, de tecnologías de la información, así como centros médicos.

v. Los residentes de Morelos a su regreso también suelen desempeñar actividades laborales tanto en el sector turístico que es el que predomina en la zona como en agricultura. Debido a su buen clima en mayor parte del año y condiciones hidrográficas, el Estado de Morelos es productor de semillas como maíz, frijol, cacahuates, de algunos frutos, de caña de azúcar, de flores de ornato y demás productos agrícolas, por tanto, no es de extrañarse que muchos migrantes y su familia se dedican a labrar la tierra o a emplearse como jornaleros y replicar las técnicas que aprendieron en Canadá.

El segundo grupo corresponde a los Estados de Campeche y Chiapas, estos Estados se encuentran en el Sureste Mexicano, el índice de rezago social para estas Entidades es de los más altos en el país. Las actividades económicas predominantes en la región son la agricultura y el turismo, como la muestra exclusivamente incluye a jornaleros se puede asimilar que estos tienen extensiones de tierras, dado a que los asentamientos humanos en esas zonas son más dispersos y la plusvalía (exceptuando las capitales, zonas turísticas y playas) es menor, se considera que los encuestados de esas zonas pueden ser propietarios de extensiones de tierra superiores aprovechando del clima e hidrografía excelentes para la actividad agrícola. La idea de los jornaleros del sureste puede ser incrementar la producción de sus tierras y poder mercar sus productos, para ello heredan el conocimiento adquirido a sus hijos y esposa para que sepan labrar la tierra de manera adecuada mientras ellos están en Canadá y a su retorno les enseñan técnicas nuevas que seguramente les van a ayudar en los rendimientos de cosechas.

Lamentablemente, como lo informa INEGI (2018), Chiapas es el estado con mayor rezago educativo, debido a la falta de infraestructura en la entidad y a los extremadamente bajos ingresos promedio que tienen los habitantes. Caso similar, en Campeche CONEVAL (2016) informa que el porcentaje de la población en pobreza es del $50 \%$.

No es la excepción, que muchos migrantes con el ingreso canadiense deciden y pueden económica-

\footnotetext{
${ }^{32}$ La colindancia geográfica de estas dos zonas determina comunicación e influencia entre ellas, por una parte, habitantes de Morelos deciden trabajar en Ciudad de México y otros de Ciudad de México tienen propiedades de descanso en Morelos, por ello la fusión de culturas es muy notable.

${ }^{33}$ Universidad Nacional Autónoma de México.

${ }^{34}$ Instituto Politécnico Nacional.

${ }^{35}$ Aunque sean foráneos, pero que estudien en la Ciudad de México.
} 
mente hablando enviar a sus hijos a escuelas en sus Estados o inclusive en la Ciudad México, este ingreso les permite incrementar el nivel de capital humano familiar con la esperanza de tener rendimientos futuros.

La siguiente variable de pertenencia al grupo de los formadores de capital humano es aquella que agrupa a los encuestados que llevan participando en el PTAT de siete a 12 años, esto es probable que suceda ya que aquellos cuya participación en el PTAT es menor a los siete años son generalmente más jóvenes que los de este grupo y por ende sus hijos también lo son, además sus carencias a la hora de emigrar pueden ser tan excesivas que los ingresos de los primeros años los utilizan para atender necesidades básicas como alimentación, vestido, vivienda y más, hasta que encuentran un punto de estabilidad asimilado por el modelo a los siete años, y además en esa etapa las exigencias de invertir en educación de los hijos comienzan a ser mayores por ello invierten ahora en educación. Aquellos que superan los 12 años en el PTAT no quiere decir que no inviertan en educación, puede ser que les apoyen a obtener hasta postgrados a los hijos, sin embargo es menos probable que esto suceda, además a mayor tiempo de permanencia en el programa, también los migrantes pueden llegar a la senectud, por tal motivo ahora sus gastos van encaminados hacia cuidados en la salud, atención a enfermedades crónico degenerativas y al consumo de bienes y servicios de esparcimiento del que se privaron años anteriores bajo el planteamiento de que "es momento de disfrutar lo trabajado".

La siguiente variable positiva es la que agrupa a migrantes que en conjunto con su familia tienen un ingreso mexicano extra al canadiense de entre $\mathrm{CAD} \$ 1,501$ a CAD $\$ 4,000$ anuales, lo que representaría de MXN\$22,870.61 a MXN\$60,148.20 al tipo de cambio de hoy ${ }^{36}$. Estos individuos los podríamos considerar dentro del grupo intermedio o de la medianía comparado con los que tengan menores o mayores ingresos mexicanos. Esta medianía los hace ser precavidos y tener una cultura de ahorro, aquellos que tienen ingresos menores en ocasiones no pueden ahorrar o invertir para la formación de capital humano o inversiones físicas más allá de lo ganado en Canadá y los que tienen ingresos superiores cuando están en México suelen adoptar vicios y organizar eventos sociales con amigos, familia, o en el pueblo ${ }^{37}$ para demostrar a sus vecinos que tienen un nivel de vida fijado por el consumo general superior a ellos, o bien suelen malgastar dicho dinero en consumo de bienes de lujo como alcohol cigarros, viajes, camionetas, etc., por tanto se vuelve improductivo ese ingreso.

Es preciso reafirmar que esta variable es complemento del ingreso canadiense, por ningún motivo se afirma que un jornalero mexicano exclusivamente con el ingreso en México podrá o no podrá ser formador de capital humano, tomamos como complemento el ingreso mexicano porque para el 100\% de la muestra dicho ingreso es menor al canadiense.

\footnotetext{
${ }^{36} \mathrm{MXN} \$ 15.04$ por CAD\$1 dólar. Consultado en www.banxico.gob.mx. 31 de octubre de 2018.

${ }^{37}$ Se tiene evidencia por ejemplo en el caso de la comunidad de San Felipe del Progreso, Estado de México, que cada familia con ingresos medios y altos dona para la fiesta patronal castillos de fuegos artificiales, increíblemente las familias con migrantes son los que demuestran mayor participación y apoyo comprando los más grandes y costosos.
} 
La siguiente variable es el grupo que captura al ingreso neto canadiense que va CAD $\$ 10,000$ a CAD\$14,000 por temporada, esto sería entre MXN\$150,370.50 a MXN\$210,580.70. Es evidente que dicho ingreso es mucho más elevado a lo que aspira ganar un jornalero en México, por tanto, ellos pueden tener mayores y mejores opciones de consumo e inversión. Evidentemente a mayor ingreso es mayor la probabilidad de que puedan destinar una mayor suma de dinero a la inversión en capital humano, podrán mandar a sus hijos a mejores escuelas, podrán tener maquinaria agrícola que les permita aplicar los conocimientos tecnológicos que aprendieron en Canadá, podrán comprar más terreno, o financiar algún negocio y ese nuevo ingreso podrá apoyarles en la formación de capital humano futuro. También quienes tienen mayores ingresos podrán acceder a mejores servicios de salud preventiva y podrán tener un mayor gasto en medicinas (cuando las requieran) lo que eleva su calidad de vida ante algún padecimiento crónico degenerativo y podrán acceder a mayores experiencias o capacitaciones informales.

Las últimas dos variables tienen un peso analítico sumamente importante para efectos de validar el articulo, la primera corresponde al total de años que cada individuo ha participado en el programa, y la segunda menciona el estado de residencia de cada migrante. Entendemos que ambas variables incluyen al 100\% de los encuestados en sus observaciones, por tanto, se asume lo siguiente: por cada jornalero mexicano que decida participar en el PTAT en lugar de continuar trabajando en México o migrar a otro país bajo otras condiciones, el nivel de capital humano de él y de su familia tendrá efectos positivos, es decir por sus características y regulación, el programa es formador de capital humano.

Esta formación va encaminada a dos rubros, el primero vinculado al ingreso monetario, dado que el ingreso neto por temporada que tienen los migrantes (sin importar si recibe bono o no, también sin importar si gana exactamente el promedio de ingreso o más), es extremadamente superior a lo que aspiran ganar en México, por ende, pueden invertir más en factores del capital humano como escolaridad y sus costos directos e indirectos, condiciones de salubridad y gasto en medicinas, o en tener experiencias como viajes, visitas a museos, y más.

Y por el lado no medible, los migrantes en Canadá reciben cursos y capacitaciones en cuanto a innovaciones tecnológicas para la producción agrícola, y también muchos de ellos están aprendiendo inglés o francés (en la provincia de Quebec), esto ya que los trabajadores que hablan el idioma del empleador pueden servir de intermediarios entre los demás trabajadores y el patrón y son considerados de un nivel superior, sube su nivel de ingreso y cambia su actividad hacia una de mayor confianza y en ocasiones con menores riesgos laborales. Al efectuar el retorno, ellos comparten sus conocimientos y experiencias con los suyos, esa parte del conocimiento indirecto se va quedando grabada en la familia y después las aspiraciones y forma de vida son definitivamente diferentes a las que tenían antes de migrar. La réplica en la experiencia laboral es un punto muy fuerte, algunos migrantes 
que contratan jornaleros en su pueblo para que atiendan sus cultivos inclusive transmiten técnicas canadienses $^{38}$ que mejoran la productividad agrícola y con ello las ganancias, entonces se encuentra plenamente identificado que el PTAT efectivamente es un motor para formar capital humano en las familias mexicanas.

\subsection{Interpretación de resultados: análisis de los factores con impacto negativo.}

Los factores con impacto negativo derivados del modelo aplicado se presentan en el cuadro 2.

Cuadro 2

Factores de impacto negativo en la formación de capital humano

\begin{tabular}{|c|c|c|c|}
\hline Variable & Nombre & $\begin{array}{c}\text { Signo del } \\
\text { coeficiente } \\
\text { exponencial }\end{array}$ & $\begin{array}{c}\text { Valor del } \\
\text { coeficiente } \\
\text { linealizado }\end{array}$ \\
\hline $\mathrm{X}_{14}$ & DUMFrecEnvDin2 & - & 0.4 \\
\hline $\mathrm{X}_{12}$ & DUMIngresoHora & - & 0.365 \\
\hline $\mathrm{X}_{11}$ & DUMPromHrsSemBaja1 & - & 0.317 \\
\hline $\mathrm{X}_{7}$ & DUMEdad_43mas & - & 0.096 \\
\hline $\mathrm{X}_{16}$ & DUMGastConsumo2 & - & 0.077 \\
\hline $\mathrm{X}_{8}$ & TrabajoUSA & - & 0.036 \\
\hline $\mathrm{X}_{15}$ & DUMGastoConsumo1 & - & 0.024 \\
\hline $\mathrm{X}_{6}$ & DUMEstNac30 & - & 0.019 \\
\hline
\end{tabular}

Fuente: Elaboración propia.

El primer factor que representa una propensión a no formar capital humano es el que agrupa a los miembros de la muestra que envían remesas a México de manera quincenal. El motivo de esta baja formación es que entre más cercana sea la frecuencia del envío menor disposición al ahorro tendrán las familias y destinaran mayor parte de estas remesas a gasto corriente, cosa que altera la inversión para la formación de capital humano. No se tiene frecuencia ideal en la muestra ya que con la regresión ninguna de las frecuencias mostró evidencia de formación, tal vez se requiera capturar la opción trimestral o "al final de la temporada" para que exista una periodicidad que en realidad surta efectos en la formación positiva.

El siguiente factor indica a los migrantes que reciben por hora un ingreso inferior al promedio de todos los trabajadores encuestados, este factor reafirma que, ante menores ingresos, menor cantidad se podrá destinar para invertir en educación. Otro factor considerado dentro del mismo análisis

\footnotetext{
${ }^{38}$ Siempre y cuando sean compatibles con el tipo de suelo, los cultivos y demás condicionantes para esta actividad o bien si es que cuentan con tecnología similar a la que utilizan en Canadá.
} 
captura el rango de horas mínimo que se trabajó en semana de temporada baja, esto afecta a la formación de capital humano, dado que perjudica al ingreso y con ello los efectos colaterales. Pero también como otra opción, cabe la posibilidad de que, en semana baja, se reduce la intensidad de trabajo y los jornaleros tienen mayor tiempo de ocio, entonces ese tiempo no lo están usando para aprender cosas nuevas en materia laboral, ni tampoco están estudiando un idioma nuevo, será bueno que los empleadores en semana baja pudieran motivar a sus jornaleros a estudiar algunas técnicas o manuales para la agricultura que posteriormente vayan a ocupar en la graja.

A continuación se presenta como factor cuya incidencia se encuentra orientada a la no formación de capital humano el grupo de edad de los trabajadores más veteranos, aquellos que tienen de 43 años en adelante, también esto reafirma parte de lo comentado anteriormente, debido a que son los más seniles y se encuentran en lo que nosotros llamaríamos la tercera etapa, asimilando que la primera fue atender sus necesidades básicas, la segunda inversión en capital humano y capital físico y la tercera ya está asociada a disfrutar de su ingreso, a adquirir bienes por satisfacción más que por ser redituables, es decir ellos ya invirtieron ahora quieren disfrutar lo que trabajan.

Las variables gasto en consumo de CAD \$1,700 a CAD \$3,000 y de CAD \$3,001 a CAD \$4,999 son definitivamente no formadoras de capital humano, con esto no se está diciendo que exista un óptimo de gasto en consumo o que sea necesario que los migrantes disminuyan este gasto, a final de cuentas la distribución del gasto con base en su ingreso la racionalizan ellos y como agentes económicos que son, se supone que toman las mejores decisiones, sin embargo la técnica nos está proponiendo que cualquier gasto en consumo en lugar de inversión en capital humano lógicamente va a afectar a la formación de este capital, por ello se sugiere a los trabajadores racionalizar la composición de su gasto, atender sus necesidades básicas y vivir con comodidad, pero no dejar a un lado el monto a invertir, recordando que dicha inversión efectivamente tendrá rendimientos crecientes futuros y es un acelerador de la economía.

Los migrantes que han trabajado en Estados Unidos previamente al PTAT se inclinan a no ser formadores de capital humano. Se asocia este resultado a malas costumbres adoptadas por los migrantes con anterioridad, generadas por las condiciones sociales que implica migrar de forma ilegal. Abundando sobre esta premisa, en principio afecta que no llevan un contrato de trabajo, no tienen preestablecidos ni horarios, ni ingresos, ni prestaciones, etc. Además, generalmente ellos son motivados por una red, ya sea de amigos, parientes o conocidos que ya están trabajando allá. Entonces al llegar buscan estabilizarse y posteriormente comienzan a tener ingresos, los primeros meses o años envían dinero de forma periódica, conforme pasa el tiempo, se torna irregular el envío de remesas a México, el posible motivo de esto, es porque algunas colonias de mexicanos en USA tienen la característica de juntarse para beber, fumar, consumir drogas, en algunos casos hasta acceder a la prostitución y también suelen adquirir compromisos maritales. Todas estas posibles razones cambian la forma en 
que administran sus ingresos y les disminuye en cantidad o imposibilita a enviar remesas familiares. Otro problema que tienen, es que los migrantes de USA ilegales no regresan cada fin de temporada a México, pasan años y años sin retornar y por tanto no están enfocados en aprender para replicar ese aprendizaje a su regreso, tampoco heredan su conocimiento ya que sus hijos crecen sin la figura paterna o materna según sea el caso, les es indiferente que estudien o no, a final de cuentas ellos mandan el dinero excedente después de sus gastos en USA y el cónyuge es el encargado de administrarlo. Aunque existe evidencia de casos exitosos que han financiado PyMES, que han realizado inversiones en capital físico, inversiones en capital humano, etc., la ideología del migrante ilegal en USA es hacer inversiones en bienes muebles e inmuebles como casas muy grandes, o comprar vehículos de lujo, mandar ropa y/o electrodomésticos y cuando logró esos objetivos retorna a México, con la diferencia de que no aspiran a jubilarse por el gobierno de aquel país y no tienen una relación con su empleador, los migrantes ilegales son desconocidos, aventureros y discriminados.

Finalmente, los migrantes nacidos en el Estado de Veracruz tienen una probabilidad alta de no ser formadores de capital humano, tal vez esto depende de cuestiones ideológicas o sociológicas que los hacen destinar sus ingresos a otras cosas menos a la formación de capital humano, o bien no tienen réplica de las experiencias tal vez por la baja compatibilidad de cultivos.

\subsection{Valoración de la bondad de ajuste estadístico del modelo.}

\section{a. El bloque 1 del modelo.}

Se realizó con el método condicional por pasos hacia adelante, siendo este una técnica automatizada en la que el programa va introduciendo los factores en el modelo, empezando por aquellas cuyo coeficiente de regresión tiene mayor significancia estadística. Al ser un procedimiento iterativo en cada paso va reevaluando la significancia de la estadística de cada coeficiente, pudiendo eliminar e incluir factores.

\section{b. Prueba ómnibus sobre los coeficientes del modelo. ${ }^{39}$}

El cuadro 3 contiene los resultados del modelo, el paso corresponde al cambio de verisimilitud (-2LL) entre pasos sucesivos en la construcción del modelo, contrastando la hipótesis $H_{0}$. El bloque mide el mismo cambio, pero entre bloques sucesivos de entrada en el modelo y finalmente el Modelo evalúa el cambio entre el modelo inicial que solo contempla a la constante contra el modelo final. ${ }^{40}$ Observamos que las tres medidas de significancia estadística que nos otorga el programa son menores a 0.05 , por tanto, decimos que se rechaza $H 0$, ya que los coeficientes de las variables son diferentes de cero indicando que no existe mejor modelo posible. 
Cuadro 3

Pruebas ómnibus sobre los coeficientes del modelo

\begin{tabular}{|l|l|r|r|r|}
\hline \multicolumn{2}{|c|}{} & \multicolumn{1}{|c|}{ Chi cuadrado } & Gl & \multicolumn{2}{c|}{ Sig. } \\
\hline \multirow{3}{*}{ Paso 17} & Paso & 4.397 & 1 & 0.036 \\
\cline { 2 - 5 } & Bloque & 140.437 & 17 & 0.000 \\
\cline { 2 - 5 } & Modelo & 140.437 & 17 & 0.000 \\
\hline
\end{tabular}

Fuente: Elaboración propia.

c. Validación global del modelo.

El resumen del modelo y los principales descriptores se muestran en el cuadro 4 y párrafos siguientes.

Cuadro 4

\section{Resumen del modelo}

\begin{tabular}{|l|c|c|c|}
\hline Paso & $\begin{array}{c}\text {-2 log de la } \\
\text { verosimilitud }\end{array}$ & $\begin{array}{c}\text { R cuadrado de Cox } \\
\text { y Snell }\end{array}$ & $\begin{array}{c}\text { R cuadrado de } \\
\text { Nagelkerke }\end{array}$ \\
\hline 17 & $134.041^{\mathrm{a}}$ & 0.421 & 0.641 \\
\hline
\end{tabular}

Nota: La estimación ha finalizado en el número de iteración 7 porque las estimaciones de los parámetros han cambiado en menos de 0.001 .

Fuente: Elaboración Propia.

i. $\quad-2 \log$ de la verosimilitud (-2LL). ${ }^{41}$ Mide el nivel de ajuste que tiene el modelo a los datos, cuanto más pequeño sea este valor mejor será el ajuste del modelo. En el caso de la tabla observamos un valor correctamente aceptable.

ii. $\quad$ R cuadrado de Cox y Snell. Es el coeficiente de determinación utilizado para estimar la proporción de varianza de la variable dependiente explicada por las variables exógenas, procede comparando (LL) ${ }^{42}$ del modelo respecto al (LL) de un modelo lineal. En nuestro modelo expresa que el $42.1 \%{ }^{43}$ de la variación en el indicador sobre la formación de capital humano es explicada por el conjunto de factores exógenas en la función.

iii. R cuadrado de Nagelkerke. Es una versión corregida ${ }^{44}$ del $R$ cuadrado de Cox y Snell, también es de utilidad para definir la bondad de ajuste del modelo, en particular para nuestro modelo

${ }^{39}$ Convierte una prueba normalizada a una prueba Chi Cuadrada mediante la aplicación de máxima verosimilitud

${ }^{40}$ (-2LLModeloOriginal) - (-2LLModeloFinal).

${ }^{41}$ También interpretado como la desviación del modelo.

${ }^{42}$ Log de la verosimilitud.

${ }^{43}$ Podría parecer un porcentaje bajo, pero según Aguayo (2007) ni un modelo perfecto alcanza el 100\% de explicación, dado que la prueba se realiza comparando un modelo exponencial con uno lineal, el margen de desviación resulta significativo en este valor. Citado en (Hair, Anderson, Tatham, \& Black, 1999).

${ }^{44}$ Se dice que es una versión corregida debido a que contempla los valores de la prueba de manera que sean estimados lineales y puedan llegar a tener un ajuste entre 0 y $100 \%$. 
expresa que $64.1 \%$ de la variación en el indicador de formación de capital humano es explicada por el conjunto de factores independientes, el valor es significativamente alto y aceptable para las predicciones e interpretaciones que el modelo enuncia. Este valor es comparado con el coeficiente de correlación de Pearson en la regresión lineal.

d. Prueba de Hosmer y Lemeshow.

Cuadro 5

Prueba de Hosmer y Lemeshow

\begin{tabular}{|l|r|r|r|}
\hline Paso & Chi cuadrado & gl & \multicolumn{1}{c|}{ Sig. } \\
\hline 17 & 6.858 & & 8 \\
\hline
\end{tabular}

Fuente: Elaboración propia.

donde:

$$
\begin{aligned}
& H_{0} \text { :El modelo se no ajusta a la realidad: Sig }<.05 \\
& H_{1} \text { :El modelo se ajusta a la realidad: Sig >.05 }
\end{aligned}
$$

Con los datos del cuadro 5 se rechaza la H_0 es decir realmente el modelo se ajusta a la realidad, y existen diminutas discrepancias entre los valores observados y aquellos pronosticados por el modelo. Para corroborar esta prueba se muestra la tabla de clasificación a continuación.

Cuadro 6

Tabla de clasificación

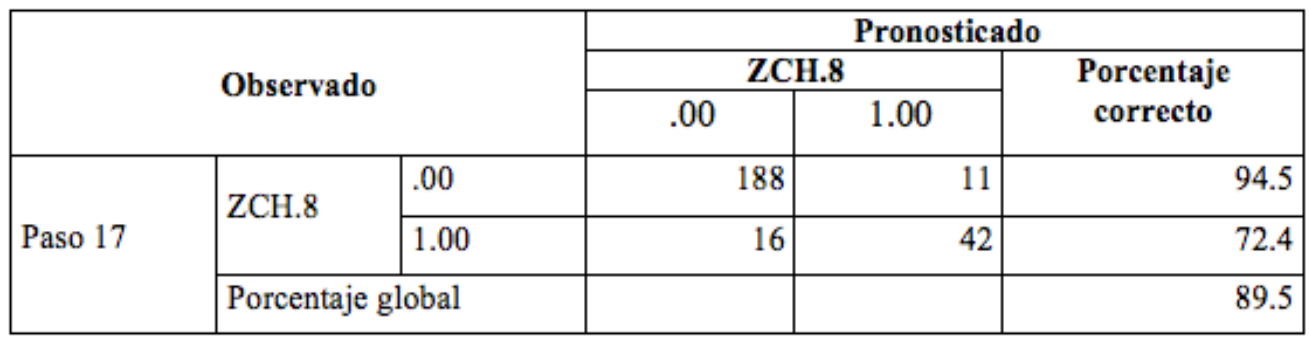

Nota: El valor de corte es 0.500 .

Fuente: Elaboración propia. 
La clasificación del cuadro 6 muestra el comportamiento final de los datos, entre los observados y los pronosticados.

El modelo tuvo la capacidad de clasificar las observaciones de la siguiente manera:

a. Los No Formadores de capital humano 0 .

i. 188 migrantes fueron observados y pronosticados efectivamente como "No Formadores.

ii. 11 migrantes más fueron observados como No Formadores pero pronosticados como Formadores.

iii. Tenemos que, de cada 100 observaciones, 95 de estas responden al ajuste correcto entre observado y estimado.

b. Los Formadores de capital humano 1 .

i. 42 migrantes fueron observados y pronosticados efectivamente como formadores.

ii. 16 migrantes más fueron observados como Formadores, pero pronosticados como No Formadores.

iii. El ajuste correcto en este grupo fue de 72 por cada 100 observaciones.

c. De manera general el modelo clasifica entre observados y pronosticados al $89.5 \%$, es decir 90 encuestados de cada 100 han sido clasificados correctamente, dato que supera las expectativas quedando el modelo como buen clasificador.

e. Prueba estadística de las variables. (estadístico de Wald.)

Esta prueba mide el nivel de significancia estadística que tienen las variables en conjunto con sus coeficientes estimados, para definir si la interpretación de pertenencia hacia el grupo $l$ de los formadores de capital humano o al grupo 0 de los no formadores de capital humano.

La hipótesis es la siguiente:

Ho:Las variables son significativas: Sig $<.05$

$H_{1}:$ Las variables no son significativas: Sig>.05

Las variables enunciadas en los cuadros 1 y 2 , presentan significancia estadística. 


\section{$\supset$ 7. Conclusiones.}

El argumento de la investigación se encontró encaminada a determinar los factores exógenos que impactan en la formación de capital humano en los trabajadores mexicanos que se encuentran inscritos en el programa migratorio internacional y regulado, el PTAT.

Según el contexto del tiempo, la migración en el PTAT es temporal y reiterada, dado que en el contrato de trabajo a cada miembro se le especifica el periodo por el que fue contratado, la fecha de regreso a México y al final el empleador decide sí los volverá a llamar para la siguiente temporada, destacando que en este programa los migrantes tienen un alto grado de libertad pues la decisión de migrar es personal, aunque existen condiciones laborales que no les permiten el libre cambio entre empleadores, la libertad de decisión para desplazarse es suya.

Teóricamente hablando, el PTAT muestra absoluta concordancia con diversas teorías sobre migración, enseguida se enuncia por teoría los apegos y desapegos que presenta:

a. a. Gran parte de los jornaleros manifestó que su familia tiene ingresos mexicanos, ya sea por actividades dentro o fuera del sector agrícola cuando ellos retornan o también gracias a la participación del cónyuge o los hijos en alguna actividad productiva también dentro o fuera de la granja. Esto nos dice varias cosas, en principio que el ingreso mexicano por únicamente ser jornalero no le es suficiente a una familia, motivo por el cual deben acceder a oficios o actividades secundarias y más de un miembro de la familia, a pesar de todo ello, familias que dependen mayormente de los ingresos por cultivar su tierra están a "la bendición de Dios" climatológicamente hablando, debido a las bajas condiciones de infraestructura agrícola particularmente en el sureste mexicano. Esto nos indica que realmente el migrar y obtener un ingreso en Canadá para los jornaleros o campesinos es una forma de proteger el ingreso de su familia ante la incertidumbre y en acuerdo con el postulado sobre las decisiones familiares para migrar, existe relación de la teoría de la nueva economía de la migración laboral con el PTAT.

b. El programa se crea debido a la demanda insatisfecha de mano de obra en el sector agrícola canadiense, la composición del mercado laboral agrícola en México tiene carencia de oportunidades, rezago social e incertidumbre laboral, además de que el interés por esta actividad va en constante decremento, por ello los agricultores y jornaleros de las zonas con mayor índice de ruralidad en cada entidad aprovechan en su mayoría la agricultura de autoconsumo o trabajan para terratenientes y agro empresas, aspirando a ganar de 1 a 2 salarios mínimos diarios. En conjunto es sabido que Canadá tiene índices de desarrollo superiores a México y en cuanto a niveles de capital humano superiores también, por tal motivo la concentración laboral de su población se encuentra en el sector terciario de la economía ya que para los canadienses el trabajo de jornalero es denigrante, riesgoso, mal remunerado y no están dispuestos a asumirlo. Ante tal escenario existe dualidad en los mercados 
laborales en contexto, por ende la teoría de los mercados duales de trabajo nos aproxima ciertamente al panorama migratorio del PTAT.

c. Se observa que la teoría de las redes migratorias ha dejado ambigua la información sobre la creación de redes patrón-empleador, donde no necesariamente la información entre connacionales es indispensable para elegir migrar, en este contexto se establece que la decisión de continuar en el PTAT depende del migrante y del empleador. Sin embargo la restricción que se genera, es que al ser un programa migratorio regulado, las autoridades que llevan las directrices del programa en conjunto con la autoridad migratoria podrían en algún momento romper dicha red, si es que el jornalero mexicano incumple con las disposiciones que son periódicamente actualizadas.

d. Debido al análisis del trabajo referente al PTAT, el postulado de la teoría de la acumulación causal donde enfatiza que la distribución regional del capital humano se volverá heterogénea, y el lugar de origen quedará agotado en cuanto a capital humano y los lugares destino se dotaran de capital humano de forma indirecta, no es válida dado que en principio se tienen límites en los niveles de escolaridad para que efectivamente los migrantes sean jornaleros y no personas con educación superior, en segunda el capital humano adquirido en Canadá puede tener réplica en México cada fin de temporada que retornan los participantes, pero esta transmisión de la educación informal dependerá de cada individuo y su familia.

Las remesas que envían los trabajadores agrícolas temporales en Canadá a México son de suma importancia, para el año 2009 sumaron alrededor de CAD\$148,160,095 millones. Esta cifra tiene impactos a escala microeconómica, regional y macroeconómica. Tal como lo redactó Carvajal, Ángeles \& Rodríguez (2011) y Muñoz (2011), el uso que los migrantes les dan a las remesas va desde el gasto corriente, hasta diversas manifestaciones de inversión, por ejemplo:

1. Inversión en bienes duraderos, como lo es la compra de terrenos, la compra o remodelación de casa.

2. Inversión en bienes de capital, como puede ser la compra de vehículos, maquinaria y herramienta.

3. La formación de pequeños negocios o empresas. Y por último,

4. La inversión en capital humano que es la más importante para fines del articulo, con base en los resultados del modelo se puede asegurar que los inscritos en el PTAT se encuentran económicamente y socialmente en condiciones superiores para realizar inversión en este concepto que antes de migrar y comparados con jornaleros que se quedaron en México. 
La visión critica de las remesas acierta en que al recibirlas las familias vinculadas al PTAT son esencialmente un ingreso trasladado que les permite en ciertos casos mantener constante o incrementar los niveles de consumo e inversión de los receptores, siendo poco susceptibles ante eventualidades sociopolíticas locales. Por otro lado, la conceptualización de esta visión se encuentra poco atinada, debido a que da evidencia de la baja probabilidad que tienen las remesas de servir para financiar inversiones productivas dada la falta de participación de instituciones gubernamentales o financieras en la región, ya que se ha analizado y descubierto que gracias al PTAT, los migrantes culturalmente, socialmente y económicamente saben diversificar mejor su gasto y tienen posibilidades de invertir, no solo en activos tangibles sino en capital humano, y que además, esta inversión sí va a generar un efecto multiplicador en la economía vía remesas, a diferencia de lo que describe Binford (2002) quien hace alusión a que la única forma que acelera la economía es debido a que la restricción presupuestaria es menor y la propensión al gasto es mayor, entonces incentiva el consumo y genera una especie de flujo circular monetario.

Finalmente corroborando el objetivo del documento, las remesas del PTAT son un motor que incrementa la inversión para la formación de capital humano. Para este análisis y a partir de aquí, vincularemos a la migración, las remesas y a los factores del capital humano para describir los impactos positivos encontrados.

Para iniciar, se recuerda que las remesas son el medio contable producto de la migración, entonces estas generalmente son monetarias o en especie, pero, el cuestionamiento ahora será ¿Qué sucede con las remesas intangibles? ¿Tienen algún impacto en la economía?

Hoy con certeza se puede responder que sí lo tienen, y ese impacto va ligado también a la formación de capital humano. El capital humano como se ha hecho hincapié en todo el artículo incluye a los factores educación, experiencia y salubridad y para incrementar la dotación de estos factores es necesario invertir tiempo y recursos monetarios. Generalmente para educación, se invierte tiempo medido en años de escolaridad, y recursos financieros en cuanto a gasto en colegiaturas, transporte, materiales y más.

Los seres humanos nacemos con una dotación inicial de intelecto y salud, para mantener y fomentar la salud debemos invertir recursos económicos en alimentación, medicinas, revisiones médicas, esparcimiento, calidad de vida, ejercicio, y más. Pero para mantener el intelecto, debemos dotarlo de experiencias y conocimientos (extra a la educación formal), que se van adquiriendo a lo largo de la vida, ante la sana convivencia social, por capacitaciones, por experiencia laboral y otras tantas fuentes que alimentan la capacidad humana.

Dicho lo anterior, un jornalero del PTAT, cuenta con ingresos superiores a los que aspiraba obtener en México por la misma actividad económica, motivo por el cual, su propensión a invertir en las variables parte de los factores que demandan recursos financieros es estrictamente mayor. 
Por otro lado, el nivel de cultura, tecnología y forma de trabajo en Canadá es diferente comparado con México, se puede decir que ellos dejan a un lado los procesos artesanales e introducen técnicas innovadoras para incrementar la productividad del campo. Un jornalero mexicano en Canadá aprende a manejar maquinaria, tipos de tierras y cultivos que en México tal vez no había puesto en practica, por ejemplo, la fresa, la apicultura, las flores de ornato, etc. Estas experiencias laborales, el migrante al retorno las trasmite con su familia, generándoles la incertidumbre de poder adoptar las técnicas que les sean posibles dadas las condiciones climatológicas, hidrológicas y financieras en México, cambiando su forma de producir y eso es lo importante ya que la experiencia que ellos tienen la están replicando en sus regiones. Además de la réplica, trasmiten el conocimiento a su familia, amigos o trabajadores, ya que alguien se deberá encargar de sus predios cuando ellos vuelvan a Canadá a trabajar.

Otros vínculos que se tienen es que a mayor capital humano menores son los riesgos laborales debido a que la cultura de prevención incrementa y muchos otros indicadores como la productividad y a la par las tasas salariales y de ganancia se mueven positivamente ante incrementos en capital humano, es decir, se comprueba la evidencia de la propuesta de los modelos de desarrollo donde el factor educación o el factor tecnológico es el encargado de crear choques económicos que permitan a las naciones salir del estado estacionario.

Se ha encontrado con el modelo LOGIT, la demostración de la formación de capital humano en las familias receptoras tanto de manera formal como informal, los incrementos son notables y puede ser que los migrantes decidan que sus hijos estudien niveles superiores o que adopten algún oficio heredado por ellos, y ambas opciones les traerán mayores rendimientos futuros que a sus padres.

El modelo nos arroja evidencia de formación de capital humano en entidades del sureste mexicano, y precisamente las políticas de desarrollo deben estar encaminadas hacia el sureste, es una prueba más de que se está distribuyendo la riqueza y el gasto público de la nación de forma heterogénea.

Por sí solo, el modelo indica que la participación en el PTAT genera formación de capital humano en las familias receptoras, con esta afirmación no se es partidario ni se apoya a la migración como punto de salida de la trampa de pobreza, sin embargo, es una opción que considerar para lograr la estabilidad y el desarrollo. No es prudente fatalizar los escenarios, pese a que hay evidencia de maltratos, violación a los derechos humanos, injusticias sociales y racismo para los mexicanos en Canadá, estos niveles son muy inferiores a los que presenta la migración ilegal en Estados Unidos.

Para cerrar esta parte del documento, sé menciona que el PTAT es un logro ejemplar en cuanto a la dualidad de los mercados laborales y una forma sana de aprovechar los vínculos generados por la 
globalización. México se beneficia a través de las remesas de estos trabajadores y a la par Canadá equilibra su mercado primario, generando un mayor valor de la producción agrícola, lo que le permite estabilizar y satisfacer sus necesidades alimenticias en un alto porcentaje.

La investigación tuvo resultados satisfactorios, ya que, fue posible gracias a la base de datos Carvajal (2008) seleccionar variables endógenas pertenecientes a los factores Escolaridad, Experiencia y Condiciones de Salubridad descritos teóricamente por los autores Schultz $(1960,1972)$, Becker $(1975,1990)$ y Mincer $(1958,1974)$ para conformar un indicador categórico dicotómico que selecciona a los migrantes como "formadores" o "no formadores" de capital humano, la utilidad de este indicador fue poder aprovecharlo como factor endógeno y nos posibilitó la modelización posterior. De igual forma fue posible estimar un modelo de regresión logística que incluyó factores exógenos de la muestra determinando aquellos que tienen impactos positivos o negativos para la formación de capital humano entre la población de la muestra.

Por tanto, el PTAT tiene efectiva contribución en la formación de capital humano en los migrantes y su familia que específicamente se encuentran vinculados al programa por cinco o más años, ya que el modelo resalta al grupo que tienen entre siete y 12 años consecutivos participando en el programa y colocándolos como los principales formadores de capital humano.

Para finalizar se concluye demostrando la viabilidad del programa y resaltando que si bien, la migración no es la única opción que los países deben considerar para escapar de la línea de pobreza y marginación social, sí es una opción considerable cuando esta se efectúa gracias a tratados o programas internacionales y, los beneficios tanto económicos como sociales que trae consigo el firmar acuerdos como el PTAT, son mayores y permiten regular y hasta disminuir la migración laboral ilegal que es principalmente motivada por los diferenciales salariales espaciales. 


\section{Bibliografía y fuentes documentales}

Canales, A. I. (2004). El papel económico y productivo de las remesas en México. Una visión crítica. El papel económico y productivo de las remesas en México. Una visión crítica (págs. 1-17). Guadalajara : Universidad de Guadalajara.

Caropresi , M. (2014). "Evaluación a Granjas Canadienses 2014”. AtocTli(11), 11.

Carvajal Gutiérrez, L. (2008). Farm-level impacts in Mexico of the participation in Canada's Seasonal Agricultural Workers Program (CSAWP). Guelph, Ontario, Canadá: University of Guelph, Doctoral Thesis.

Carvajal Gutiérrez, L., \& Elizalde Sánchez, C. (2009). "Trabajadores Agrícolas Mexicanos en Canadá ante la Nueva Política Migratoria”. Economía Actual, 2(4), 38-41.

Carvajal, L. (2008). Farm-level Impacts in Mexico of the Participations in Canada's Seasonal Agricultural Worker Program (CSAWP). Guelph, Ontario, Canada: University of Guelph (PhD Thesis).

Carvajal, L., Ángeles, V., \& Rodríguez, Ó. (2011). "El Programa de Trabajadores Agrícolas Temporales entre México y Canadá y la inversión agrícola en el Estado de México”. Paradigma Económico, 61-84.

Arango, J. (Octubre de 2003). "LA EXPLICACIÓN TEÓRICA DE LAS MIGRACIONES: LUZ Y SOMBRA". Migración y Desarrollo(001), 01-30.

Becker, G. (1975). "Investment in Human Capital: Effects on Earnings. En T. N. Research, Human Capital: A Theoretical and Empirical Analysis, with Special Reference to Education, Second Edition (págs. 13-44)". Cambridge : the National Bureau of Economic Research.

Becker, G. S., Murphy, K. M., \& Tamura, R. F. (1990). "Human Capital, Fertility and Economic Growth". (N. B. Research, Ed.) NBER working paper(3414), 1-18.

Binford, L. (2002). "Remesas y subdesarrollo en México”. Relaciones. Estudios de Historia y Sociedad, $117-158$.

de la Fuente Fernández, S. (2011). "Regresión Logística". Universidad Autónoma de Madrid. Madrid: Facultad de Ciencias Económicas y Empresariales.

Giménez, G. (Agosto de 2005). "La dotación de capital humano de América Latina y el Caribe" . Revista de la CEPAL, 103-122.

Hair, J., Anderson, R., Tatham , R., \& Black, W. (1999). Análisis Multivariante. Madrir: Prentice Hall.

Hernández Sampieri, R., \& Fernández Collado, C. (2014). Metodología de la Investigación. (Sexta Edición ed.). Ciudad de México: McGraw-Hill / Interamericana Editores .

Martínez De Ita , M. (1997). “El papel de la educación en el pensamiento económico”. APORTES, 107-133.

Martínez Rodríguez, E. (2008). "Logit Model como modelo de elección discreta: Origen y Evolución". . Anuario Juridíco y Económico Escurialense, 469-484.

Massey, D., Alarcon , R., Durand, J., \& Gonzalez, H. (1987). Return to Aztlan: The Social Process of International Migration from Western Mexico. Berkeley: University of California Press.

Massey, D., Arango, J., Hugo, G., Kouaouci, A., Pellegrino, A., \& Taylor, J. (Septiembre de 1993). “Theories of International Migration: A Review and Appraisal". Population and Development Review, 19(3), 431-466.

Medina Moral, E. (2003). Modelos de Elección Discreta. Madrid: Documento de Trabajo .

Mincer, J. (1974). "Schooling, Experience and earning”. New York: National . 
Mincer, J. (1958). "Investment in Human Capitail and Personal Income Distribution". Journal of Political Economy, 281-302.

Muñoz Carrillo, L. (2011). Programa de Trabajadores Agrícolas Temporales México - Canadá: Costos y Beneficios. The George Washington University. Washington D.C.: The George Washington University.

Piore, M. (1979). Birds of Passage. Migrante Labor and Industrial Societies. Cambridge: Cambridge University Press.

Schultz, T. (1972). Human Capital: Policy Issues and Research Opportunities (Vol. 6). Chicago: National Bureau of Economic Research.

Schultz, T. W. (Dec. de 1960). "Capital formation by education". The journal of political economy, 68(6), 571-583.

Stark, O. (1991). "The migration of labor". Cambridge: Basil Blackwell.

Stark, O., \& Taylor, J. (1989). "Relative Deprivation and International Migration”. Demogrphy, 1-14.

Trejo García, E., \& Alvarez Romero, M. (2007). Programa de Trabajadores Agricolas Temporales México-Canada (PTAT). Centro de Documentación, Información y Análisis. Mexico: Camara de Diputados LX Legislatura.

Veraza López, A., Carreño González, I., Cervantes Zavala , A., \& Loyola Mandolini, D. (2016). Informe final evaluación de procesos del Programa de Trabajadores Agrícolas Temporales México-Canadá. Cordinación General del Servicio Nacional de Empleo . México: Secretaría del Trabajo y prevision Social .

\section{Sitios de internet consultados}

BANXICO. http://www.banxico.org.mx

CONEVAL. https://www.coneval.org.mx/coordinacion/entidades/Campeche/Paginas/Pobreza-2016.aspx

"GOVERMENT OF CANADA". Disponible en: https://www.canada.ca/en/employment-socialdevelopment/services/foreign-workers/agricultural/seasonal-agricultural/apply/mexico-spanish. html, consultado el 26 de septiembre de 2018.

INEGI. Encuesta Nacional de gastos de los hogares 2013, INEGI, consultado el 5 de septiembre de 2018, disponible en: http://www.inegi.org.mx/lib/olap/consulta/general ver4/MDXQueryDatos. asp?proy=engasto gastosajust 12

INEGI. Cuentame inegi; Poblacíon. 2018. http://cuentame.inegi.org.mx/poblacion/migracion.aspx?tema=P (último acceso: 03 de Marzo de 2018).

INEGI. 2018. http://cuentame.inegi.org.mx/poblacion/escolaridad.aspx?tema=P (último acceso: 03 de Septiembre de 2018). 


\section{Anexo 1}

Variables incluidas para la formación del indicador de capital humano

\begin{tabular}{|c|c|c|c|}
\hline Variable & $\begin{array}{l}\text { Incidencia } \\
\text { en: }\end{array}$ & Descripción & Nueva Codificación \\
\hline & \multicolumn{3}{|c|}{ Datos del Migrante } \\
\hline YearEduc & Educación & $\begin{array}{l}\text { Años de escolaridad del } \\
\text { Migrante }\end{array}$ & $\begin{array}{l}\text { Se clasifican como formadores " } 1 \text { " a los encuestados } \\
\text { que superen los } 6 \text { años de escolaridad. Caso contrario } \\
\text { " } 0 \text { " }\end{array}$ \\
\hline SpeakEng & Educación & Si el migrante habla ingles & $\begin{array}{l}\text { Los migrantes que hablan ingles (poco o fluido) } \\
\text { tendrán "1", caso contrario " } 0 \text { " }\end{array}$ \\
\hline ReadEng & Educación & Si el migrante lee ingles & $\begin{array}{l}\text { Los migrantes que saben leer ingles (poco o bien) } \\
\text { tendrán "1", caso contrario " } 0 \text { " }\end{array}$ \\
\hline RKnowNewSkills & Experiencia & $\begin{array}{l}\mathrm{Si} \text { el aprender nuevas } \\
\text { experiencias es un incentivo } \\
\text { para migrar. }\end{array}$ & $\begin{array}{l}\text { Quienes consideren que es importante o muy } \\
\text { importante aprender nuevas experiencias, se les da e } \\
\text { valor " } 1 \text { ", caso contrario " } 0 \text { ". }\end{array}$ \\
\hline SkillsLearned & Experiencia & $\begin{array}{l}\text { Si el migrante ha aprendido } \\
\text { nuevas habilidades } \\
\text { participando en el PTAT. }\end{array}$ & $\begin{array}{l}\text { Para quienes consideren haber aprendido nuevas } \\
\text { habilidades se les otorga el valor " } 1 \text { ", caso contrario } \\
\text { " } 0 \text { ". }\end{array}$ \\
\hline UsefullInMexico & Experiencia & $\begin{array}{l}\text { Si el migrante considera que la } \\
\text { habilidad aprendida es útil en } \\
\text { México }\end{array}$ & $\begin{array}{l}\text { Si considera que la habilidad aprendida es útil a } \\
\text { retorno, "1", caso contrario " } 0 \text { ". }\end{array}$ \\
\hline \multicolumn{4}{|c|}{ Variables que afectan a la familia } \\
\hline SposeEducation & Educación & $\begin{array}{l}\text { Años de escolaridad del } \\
\text { Conyugue }\end{array}$ & $\begin{array}{l}\text { Se clasifican como formadores " } 1 \text { " a los encuestados } \\
\text { que superen los } 6 \text { años de escolaridad. Caso contrario } \\
\text { "0" }\end{array}$ \\
\hline ChildEduc & Educación & $\begin{array}{l}\text { Años de escolaridad del hijo } 1 \\
\text { al hijo } \mathrm{N} \text { de cada migrante. }\end{array}$ & $\begin{array}{l}\text { Bajo la premisa de que si el } 50 \% \text { o más de los hijos ya } \\
\text { superaron el promedio de años de escolaridad de sus } \\
\text { padres o se encuentran estudiando, dotaremos de " } 1 \text { ", } \\
\text { caso contrario " } 0 \text { " }\end{array}$ \\
\hline RImproveFamLife & Salubridad & $\begin{array}{l}\text { Incrementar el nivel de vida de } \\
\text { su familia es un incentivo para } \\
\text { participar en el PTAT }\end{array}$ & $\begin{array}{l}\text { Sí el migrante considera que es importante o muy } \\
\text { importante incrementar el nivel de vida familiar, se } \\
\text { asigna el "1", caso contrario " } 0 \text { ". }\end{array}$ \\
\hline $\begin{array}{l}\text { RSendChildrenScho } \\
\text { ol }\end{array}$ & Educación & $\begin{array}{l}\text { Cuan importante es el objetivo } \\
\text { de mandar a los hijos a la } \\
\text { escuela, situación } r \text { que } \\
\text { determina la decisión de } \\
\text { migrar. }\end{array}$ & $\begin{array}{l}\text { Se les asigna "1" a los migrantes que consideren que } \\
\text { es importante o muy importante caso contrario " } 0 \text { ". }\end{array}$ \\
\hline
\end{tabular}




\begin{tabular}{|c|c|c|c|}
\hline SchoolFeesDollar & Educación & $\begin{array}{l}\text { Gasto en colegiaturas que } \\
\text { efectúa el migrante, expresado } \\
\text { en dólares canadienses }\end{array}$ & $\begin{array}{l}\text { Con base en datos de INEGI }{ }^{45} \text {, se consideran como } \\
\text { hogares formadores de capital humano, a aquellos que } \\
\text { invierten en educación más del promedio anual en } \\
\text { México que fue de CAD } \$ 391.43 \text {, quedando } \\
\text { codificados con 1", caso contrario "0". }\end{array}$ \\
\hline MedicinesDollar & Salubridad & $\begin{array}{l}\text { Gasto en medicinas que } \\
\text { efectúa el migrante y su } \\
\text { familia anualmente }\end{array}$ & $\begin{array}{l}\text { Con base en datos de INEGI }{ }^{46} \text {, se consideran como } \\
\text { hogares formadores de capital humano, a aquellos } \\
\text { que invierten en medicinas más del promedio anual } \\
\text { en México que fue de CAD } \$ 345.68 \text {, quedando } \\
\text { codificados con 1", caso contrario "0". }\end{array}$ \\
\hline $\begin{array}{l}\text { BuyWithoutCanInc } \\
\text { ome }\end{array}$ & Salubridad & $\begin{array}{l}\text { Habrías podido invertir sin } \\
\text { remesas. }\end{array}$ & $\begin{array}{l}\text { "1" Si el migrante considera que no hubiera } \\
\text { conseguido invertir sin remesas, "0" caso contrario. }\end{array}$ \\
\hline $\begin{array}{l}\text { famlivestandcompar } \\
\text { others }\end{array}$ & Salubridad & $\begin{array}{l}\text { ¿Cómo es el nivel de vida de } \\
\text { su familia comparado con } \\
\text { otros en su comunidad? }\end{array}$ & $\begin{array}{l}\text { Si el migrante considera que su nivel de vida familiar } \\
\text { es mejor o mucho mejor son formadores " } 1 \text { ", caso } \\
\text { contrario " } 0 \text { ". }\end{array}$ \\
\hline FamLivelihood & Salubridad & $\begin{array}{l}\text { ¿Cuan mejor/peor es el } \\
\text { sustento }{ }^{47} \text { de tu familia? }\end{array}$ & $\begin{array}{l}\text { Si el migrante considera que el sustento de su familia } \\
\text { es mejor o mucho mejor son formadores " } 1 \text { ", caso } \\
\text { contrario " } 0 \text { ". }\end{array}$ \\
\hline
\end{tabular}

Fuente: Elaboración propia.

\footnotetext{
${ }^{45}$ Encuesta Nacional de gastos de los hogares, Consultado el 2 de Julio de 2018, disponible en la siguiente liga: $h t t p: / / w w w$. inegi.org.mx/sistemas/Olap/Proyectos/bd/encuestas/hogares/engasto/GastosAjust2012.asp? s=est\&c=330631\&pro$y=$ engasto_gastosajust 12\%20[Roman]\%20gracias\%20me\%20es\%20util\%20la\%20encuesta\%20Mute.

${ }^{46}$ Encuesta Nacional de gastos de los hogares, Consultado el 2 de Julio de 2018, disponible en la siguiente liga: $h t t p: / / w w w$. inegi.org. $m x /$ sistemas/Olap/Proyectos/bd/encuestas/hogares/engasto/GastosAjust2012.asp? s $=$ est\&c $=330631 \&$ pro$y=$ engasto_gastosajust 12\%20[Roman]\%20gracias\%20me\%20es\%20util\%20la\%20encuesta\%20Mute.
} 


\section{Anexo 2}

\section{Ponderación de las variables para conformar el indicador}

\begin{tabular}{|c|c|c|}
\hline \multicolumn{3}{|c|}{ Escolaridad 50\% } \\
\hline Variable & Interpretación & Ponderación \\
\hline M AñosEscol & Años de escolaridad del migrante & $5 \%$ \\
\hline M Habla Ingles & $\begin{array}{c}\text { Si el migrante sabe hablar inglés, independientemente del } \\
\text { nivel. }\end{array}$ & $5 \%$ \\
\hline M Lee Ingles & Si el migrante sabe leer en inglés. & $5 \%$ \\
\hline F EscolCon & Años de escolaridad del Conyugue & $5 \%$ \\
\hline F EscolHijol,...HijoN $^{48}$ & $\begin{array}{l}\text { Escolaridad de los hijos. Expresa si los hijos han superado a } \\
\text { sus padres en nivel escolar, o bien si están cursando al } \\
\text { momento de la encuesta. }\end{array}$ & $10 \%$ \\
\hline F REnvEscueHijos & $\begin{array}{c}\text { Respuesta, sí enviar s sus hijos a la escuela es incentivo para } \\
\text { migrar. }\end{array}$ & $10 \%$ \\
\hline F GastColeg & Gasto en Colegiaturas. & $10 \%$ \\
\hline \multicolumn{3}{|c|}{ Experiencia $25 \%$} \\
\hline M RNuevasHabili & $\begin{array}{c}\text { Si el migrante tuvo como propósito migrar para aprender } \\
\text { nuevas habilidades }\end{array}$ & $10 \%$ \\
\hline $\begin{array}{l}\text { M Aprendiste Nuevas } \\
\text { Habilidades }\end{array}$ & $\begin{array}{l}\text { Si el migrante considera que ha aprendido habilidades } \\
\text { nuevas al participar en el PTAT. }\end{array}$ & $10 \%$ \\
\hline M HabiliUtil & $\begin{array}{l}\text { Si aprendió nuevas habilidades, se cuestiona si son útiles en } \\
\text { México a su retorno. }\end{array}$ & $5 \%$ \\
\hline \multicolumn{3}{|c|}{ Condiciones de Salubridad 25\% } \\
\hline F RIncreNivelVida & $\begin{array}{l}\text { Si el migrante tuvo como propósito migrar para incrementar } \\
\text { el nivel de vida de su familia. }\end{array}$ & $5 \%$ \\
\hline F GastMedicina & $\begin{array}{l}\text { Si el gasto que el migrante efectúa en medicinas es } \\
\text { significativo con base a las condiciones anteriores. }\end{array}$ & $2 \%$ \\
\hline F InverSinRem & $\begin{array}{l}\text { Si el migrante considera que pudo hacer los mismos } \\
\text { gastos/inversiones aun sin participar en el PTAT. }\end{array}$ & $8 \%$ \\
\hline F ComparaNivVida & $\begin{array}{l}\text { Si el nivel de vida de la familia del migrante es mejor/peor } \\
\text { comparado con las personas de su localidad. }\end{array}$ & $5 \%$ \\
\hline F SustentoFamiliar & $\begin{array}{l}\text { Si el migrante considera que el sustento de su familia ha } \\
\text { sido meior/peor que cuando no participaba en el PTAT. }\end{array}$ & $5 \%$ \\
\hline
\end{tabular}

Fuente: Elaboración propia.

\footnotetext{
${ }^{48}$ Para formar la variable binaria sobre educación de los hijos, se considerará lo siguiente: Si el hijo ya superó al promedio de años de escolaridad de sus padres o Si el hijo aún se encuentra estudiando, obtendremos como resultado 1, caso contrario 0 . Esto se va a efectuar para cada hijo, sin embargo al final debemos únicamente tener una variable de educación de los hijos y no una por cada hijo para simplicidad del modelo, para realizar esto aplicaremos el siguiente supuesto: "A partir de conocer el número de hijos que tiene cada migrante, vamos a sacar el promedio de los hijos que obtuvieron resultado "1" en la evidencia anterior, aquellos que superen .70 como valor promedio se les asignará el valor 1 en la función, los casos opuestos el valor $0 . "$
} 
Números anteriores:

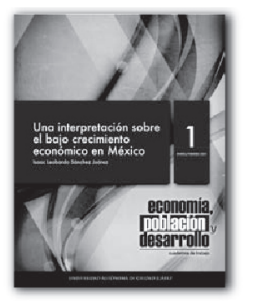

Economía, población y desarrollo.
Cuadernos de trabajo №1

Enero-Febrero 2011
Una interpretación sobre el bajo

crecimiento economico en México
Isaac Leobardo Sánchez Juárez

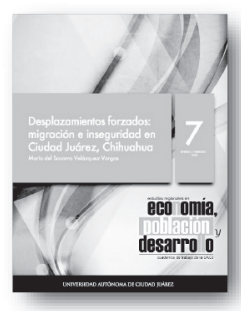

Economia, población y desarroll

Cuadernos de trabajo $\mathrm{N}$ -
Encro-Fcbrcro 2012

Desplazamientos forzados
migración e inseguridad

Ciudad Juárez, Chihuahua
Maria del Socorro Velázquez Varga

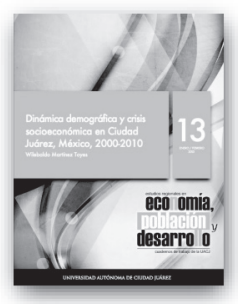

Economiá, población y desarrollo

de trabajo $N$

Dinámica demográ́fica y crisis
socieconómica en Ciudad Juáre Mexico, 2000-2010

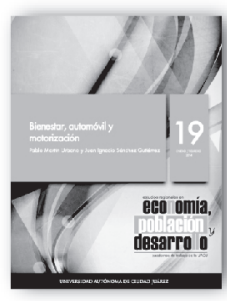

Economía, población y desarroll Enero - Febrero 2014 Bienestar, automóvil y motorización
Pablo Martín Urbano y Miosánchez Gutiérrez

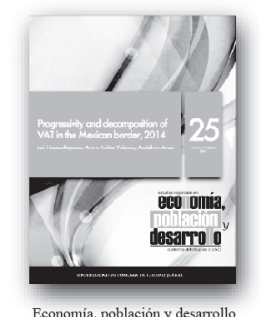

Cuadernos de trabajo No $_{0}$
Conomia,

Encro - Febrero 2015

Progressivity and decomposition of
VAT in the Mexican border, 2014 Abdelkim Araar

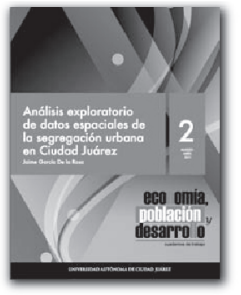

Economía, población y desarrollo.
Cuadernos de trabajo № 2

Marzo-Abril 2011

espaciales de la segregacón

Jaime Garcia De la Rosa

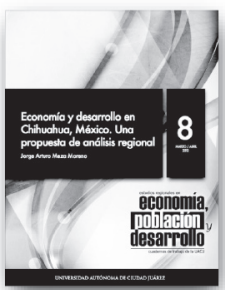

Economia, población y desarrollo

Cuadernos de trabajo №7

Economía y desarrollo en

propuesta de análisis regiona

Jorge Arturo Meza Moreno



Economía, población y desarrollo

Marzo - Abri1 2013

Capital social y desarrollo

Pablo Galaso Reca



Economia, población y desarrollo

Marzo - Abril 2014

Beneficio económico y turismo

enico. El caso de las ter
en Michoacán, Mésico

arlos Franciseo Ortiz Paniagu

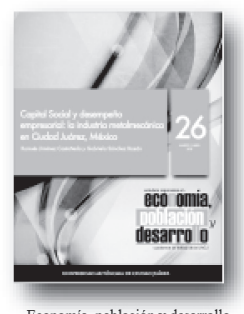

Economía, población y desarrollo

Cuadernos de trabajo № 26
Marzo - Abril 2015

Capital Social y desempeño empresa
la industria metalmecánica en

a industria metalmecánica en
Ciudad Juárez, México

Ramsés Jiménez Castañeda y
Gabriela Sáncez Bazán
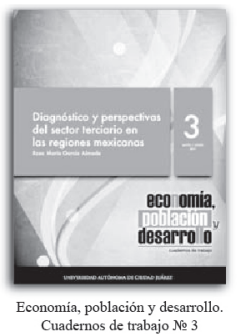

Diagnóstico y perspectivivas

regiones mexicanas
rosa Mária Garcia Almad

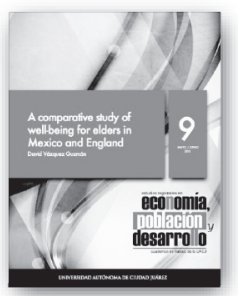

Economia, población y desarrollo

Cuadernos de trabajo № 9
Mayo - Junio 2012

A comparative study of

Mexico and England
David Vázquez Guzmán

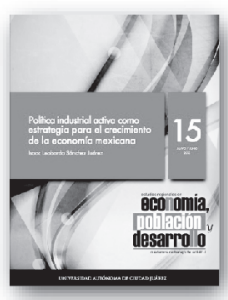

Economia, población y desarroll

Madernos de trabajo
Mayo - Junio 2013

Politica ind ustrial activa como

strategia para el crecimiento

Isaac Lcobardo Ś́nexicana
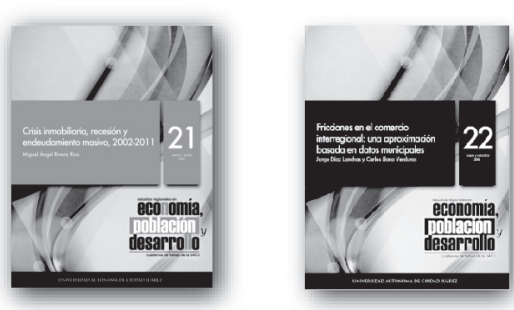

Economia, población y desarrollo

Cuademos de trabajo
Mayo - Junio 2014

Crisis inmobiliaria, recesión y
adeudamiento masivo, $2002-2011$

Miguel Ángel Rivera Rios

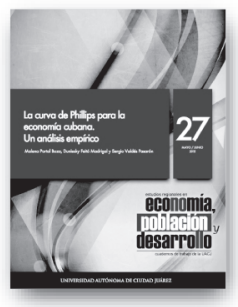

Economia, población y desarrollo

Cuadernos de trabajo № 27

a curva de Phillips para

economía cubana.

Malena Portal Boza, Duniesky Feitó

Economía, población y desarrollo.
Cuadernos de trabsio

julio-Agosto 201

Los indices IDH y FGT en la

mera década del siglo XX

Economía, población y decarrollo

Cuadernos de trabajo №
Julio - Agosto 2012

Political competition and the

edistribution in a federation

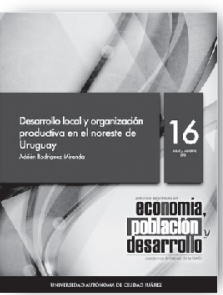

Economía, población y desarrollo

Cuadernos de trabajo №
Julio - Agosto 2013

Desarrollo local y organización
productiva en el noroeste de Urugu

Economía, población y desarrollo

Julio - Agosto 2014

Ficciones en el comercio

basada en datos municipales
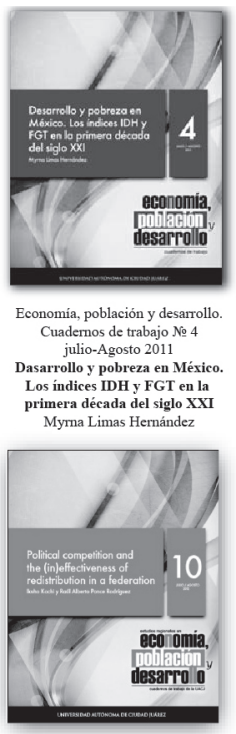

Jorge Diaz Lanchas y Carlos Llano Verduras
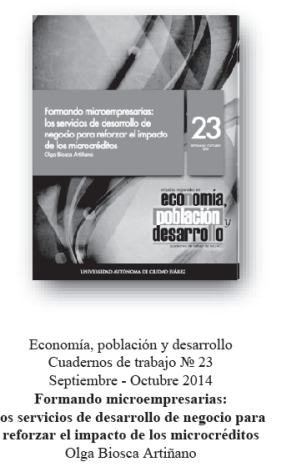

Cuadernos de trabajo № 24

El crecimiento de las regiones

el paradigma del desarrollo

divergente. Un marco térico
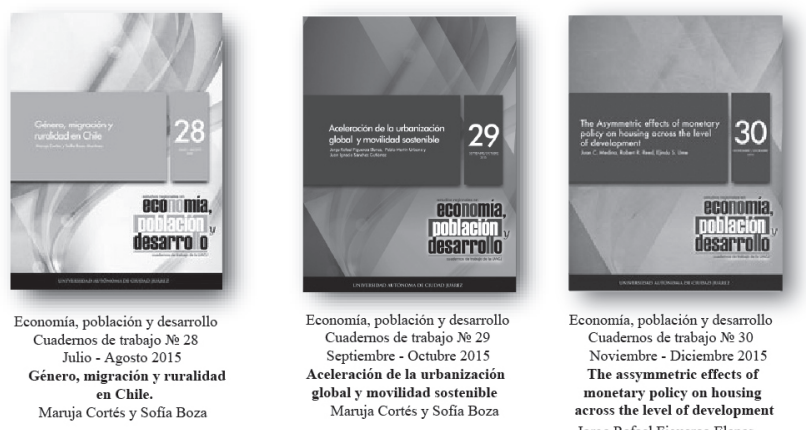

conomía, población y desarrol

Cuadernos de trabajo № 30

The assymmetric effects of

monetary policy on housing

Jorge Rafael Figueroa Elenes,

Juan Ignacio Sánchez Gutiérrez 
Números anteriores:
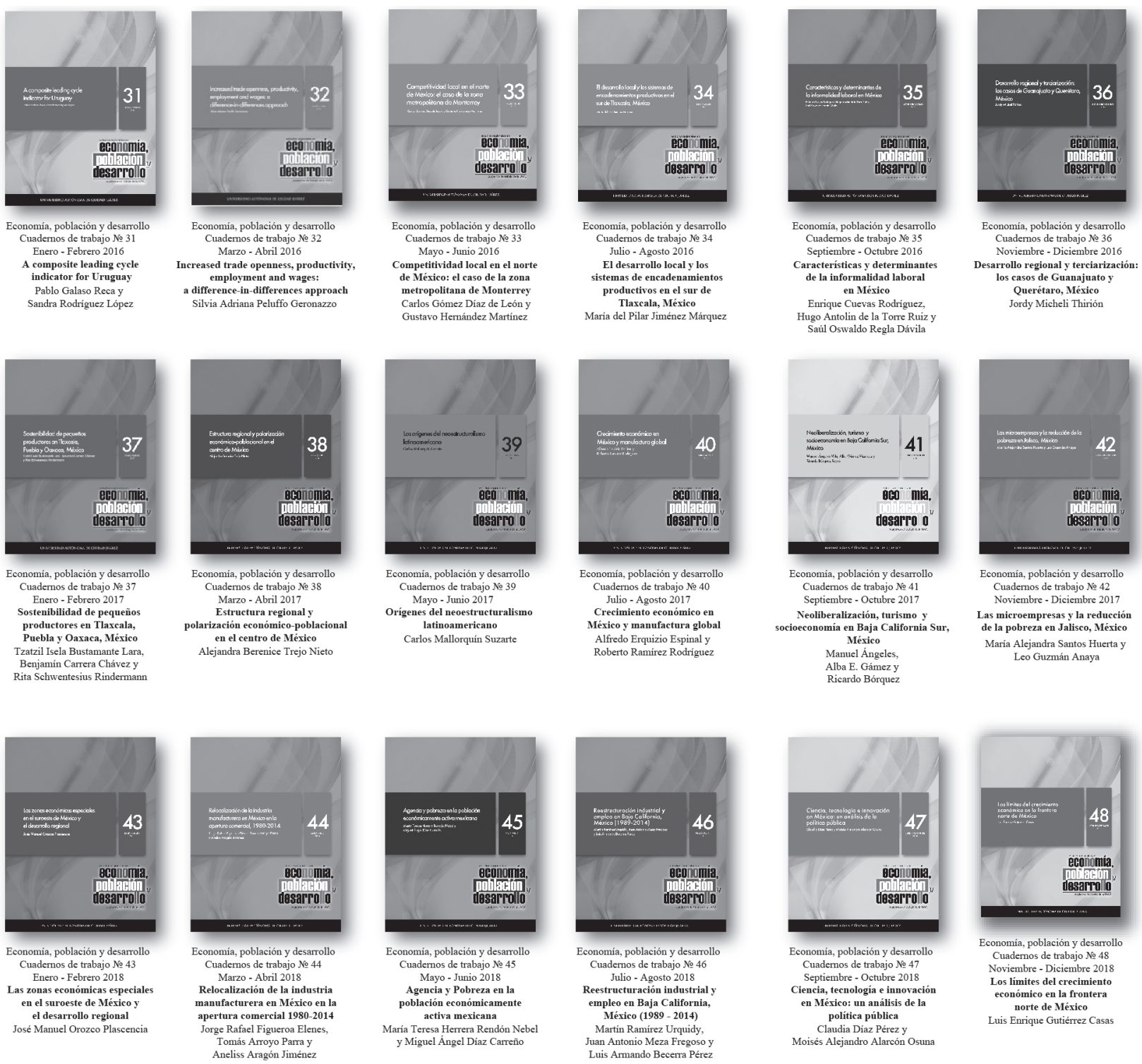

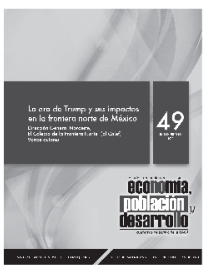

Economía, población y desarroll Cuadernos de trabajo № 19
Enero - Febrero 2019

La era de Trump y sus impactos
en la frontera norte de Mécico Dirección General Noroeste Varios autores

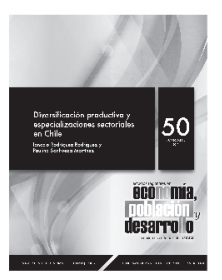

Economia, población y desarrollo Cuademos de trabajo № Marzo - Abril 2019

Diversificación productiva y
especializaciones sectoriales en Chile Ignacio Rodriguez Rodriguez
Paulina Sanhueza Martinez

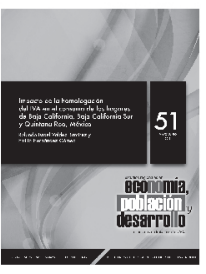

Economia, población y desarrollo Cuademos de trabajo № 51
Mayo - Junio 2019 Impacto de la homologación del IVA
en el consumo de los hogares de Baja Califoria, Baja Califoria Sur y Quintana Roo, México Rolando Israel Valdez Ramirez y
Emilio Hernández Gómez 


\section{$\rightarrow$ Normas Editoriales}

\section{Para el documento general:}

Tipo de letra: Times New Roman.

Tamaño: 11 puntos.

Interlineado: 1.5 espacios.

Títulos y subtítulos:

El texto principal en 11 puntos. Títulos 12 puntos (en resaltado). Subtítulos 11 puntos. Cada título y subtítulo deberá numerarse bajo el siguiente orden: $1,1.1,2,2.1,2.2 \ldots$

La extensión máxima de los cuadernos de trabajo será de 40 cuartillas.

La primera vez que se emplee una sigla en el texto se especificará primero su equivalencia completa y después la sigla.

\section{Hoja de presentación:}

Título:

14 puntos, centrado, resaltado.

Nombre de autor(es):

12 puntos

Resumen y abstract:

Debe incluir resumen en español y abstract (diez puntos), no mayor a 250 palabras

Palabras clave:

Incluir entre tres y cinco palabras clave, en español e inglés

Referencia del autor o autores:

Institución de adscripción, grado académico y líneas-grupos de investigación que desarrolla y a los que pertenece.

\section{Sistema de referencia de citas:}

Harvard-APA

Las citas bibliográficas en el texto deberán incluir entre paréntesis sólo el apellido del autor, la fecha de publicación y el número de página; por ejemplo: (Quilodrán, 2001: 33).

\section{Notación en sección de bibliografía y fuentes de información:}

Se deberá incluir al final del texto. Toda referencia deberá estar mencionada en el texto o notas de pie de página.

Cada referencia iniciará con el primer apellido o los apellidos, luego el nombre del autor, y después, entre paréntesis, el año de publicación seguido de un punto. Ejemplos:

Se deberá incluir al final del texto. Toda referencia deberá estar mencionada en el texto o notas de pie de página.

Cada referencia iniciará con el primer apellido o los apellidos, luego el nombre del autor, y después, entre paréntesis, el año de publicación seguido de un punto. Ejemplos:

Artículo:

Ros, Jaime (2008). "La desaceleración del crecimiento económico en México desde 1982”, en Trimestre Económico, vol. 75, núm. 299, pp. 537-560.

Libro:

Villarreal, René (2005). Industrialización, competitividad y desequilibrio externo en México. 
Un enfoque macroindustrial y financiero (1929-2010), México, Fondo de Cultura Económica. Capítulo de libro:

Castillo, Manuel Ángel (2003). "La política de inmigración en México: un breve recuento", en Manuel Ángel Castillo, Alfredo Lattes y Jorge Santibáñez (coords.), Migración y fronteras, Tijuana, El Colegio de la Frontera Norte / Asociación Latinoamericana de Sociología / El Colegio de México, pp. 425-451.

\section{Notas de pie de página:}

Se utilizarán para hacer indicaciones complementarias, aclaraciones o ampliación de una explicación. La notas de pie de página en Times New Roman, 10 puntos.

\section{Tipología de imágenes dentro del texto:}

Cuadro

Gráfica

Diagrama

Mapa

Figura

Todas las imágenes deben ser numeradas y mencionadas dentro del texto. A toda imagen debe incluirse la fuente.

Las indicaciones de la imagen: tipo y número de imagen, título de imagen y fuente se escriben en 10 puntos. En el texto poner como imagen los mapas, figuras, gráficas y diagramas -con el ánimo de no perder el formato realizado por el autor.

\section{Ecuaciones y fórmulas:}

Si se utilizan ecuaciones o fórmulas deberá utilizarse el editor de ecuaciones de Word y numerarse.

\section{Envío de trabajos}

Los trabajos deben ser enviados a la dirección de correo: lgtz@uacj.mx. Con el Dr. Luis Enrique Gutierrez Casas, editor de esta publicación.

La aceptación de cada colaboración dependerá de la evaluación de dos dictaminadores especialistas en la materia que se conservarán en el anonimato, al igual que el autor (autores) para efectos de la misma. 


\section{$\rightarrow$ Editorial Guidelines}

\section{For General Document:}

Font type: Times New Roman.

Size: font size 11 .

Paragraph: 1.5 line spacing.

Titles and subtitles: Main text font size 11. Titles font size 12 (Bold). Subtitles font size 11.

Each title and subtitle should be numbered in the following order: 1, 1.1, 2, 2.1, 2.2...

The maximum length of the workbooks will be 40 pages.

The first time an abbreviation is used in the text will be specified first complete equivalence and then stands.

\section{Front cover:}

Title:

Font size 14, centered, Bold.

Author name(s):

Font size 12.

Abstract:

It should include abstract in Spanish and abstract (font size 10), no more than 250 words.

Keywords:

Include three to five keywords, in Spanish and English.

Reference of author:

Institution of affiliation, academic degree and line-developed by research groups and belonging.

\section{Bibliographical appointment system:}

Harvard-APA

Citations in the text should include between parentheses only the author's name, publication date and page number, for example:

(Quilodrán, 2001: 33).

\section{Notation about Bibliography section and Information fonts:}

Should be included at the end of the text. All references must be mentioned in the text or footnotes page.

Each reference starts with the first name or last name, then the name of the author, and then, in parentheses, the year of publication followed by a period. Examples:

Article:

Ros, Jaime (2008). “La desaceleración del crecimiento económico en México desde 1982”, en Trimestre Económico, vol. 75, núm. 299, pp. 537-560.

Book:

Villarreal, René (2005). Industrialización, competitividad y desequilibrio externo en México. Un enfoque macroindustrial y financiero (1929-2010), México, Fondo de Cultura Económica.

Book chapter:

Castillo, Manuel Ángel (2003). "La política de inmigración en México: un breve recuento”, en Manuel Ángel Castillo, Alfredo Lattes y Jorge Santibáñez (coords.), Migración y fronteras, Tijuana, E1 Colegio de la Frontera Norte / Asociación Latinoamericana de Sociología / El Colegio de México, pp. 425-451. 


\section{Footnotes:}

Must be used to make additional indications, clarification or expansion of an explanation. The footnotes must be in Times New Roman, font size 10.

\section{Image typology inside text:}

Picture

Graph

Diagram

Map

Figure

All images must be numbered and mentioned in the text, should include the source image. The indications of the image: type and number of image, image title and source are written in 10 font size. In the text set as image maps, figures, graphs and charts-with the intention of not losing the formatting by the author.

\section{Equations and Formulae:}

When using equations or formulas should be used in Microsoft Word equation editor and numbered.

\section{Paper sending}

Entries must be sent to the email address: lgtz@uacj.mx. With Dr. Luis Enrique Gutiérrez Casas, editor of this publication.

Acceptance of each collaboration will depend on the evaluation of two examiners skilled in the art to be kept anonymous, like the author(s) for the same purposes. 
Publicacion afiliada a la

UNIVERSIDAD

AUTÓNOMA DE

CIUDAD JUÁREZ

$\begin{aligned} \text { O: } & \begin{array}{l}\text { Red } \\ \text { Iberoamericana } \\ \text { de Estudios } \\ \text { del Desarrollo }\end{array} \\ \text { RIED } & \end{aligned}$

Esta obra se editó y terminó de imprimir en

Ciudad Juárez, Chihuahua, México 
